\title{
REACCIONS SENYORIALS \\ A LA CRISI AGRÀRIA A CATALUNYA, A LA BAIXA EDAT MITJANA: ELS REMENCES
}

\author{
ASSUMPTA SERRa Clota \\ Universitat de Barcelona
}

\begin{abstract}
SUMARI
1. Introducció.- 2. La Pesta Negra: Avaluacions demogràfiques i reaccions immediates dels senyors.- 3 . Anàlisi de la crisi senyorial a través d'una forma contractual peculiar.- 4. Conclusions: Reaccions senyorials per zones geogràfiques.
\end{abstract}

\section{INTRODUCCIÓ}

Al llarg dels segles XIV y XV, el sector agrari català, com a la resta d'Europa, es veié immers en una gran crisi, deguda a les contradiccions del propi sistema feudal. Els propietaris de les terres en l'etapa anterior varen aprofitar l'augment de la producció derivat del conreu expansiu de cereals, per enriquir-se i no per augmentar el rendiment invertint en millores tecnològiques. L'augment de la producció fou fruit de l'esforç de les famílies pageses, que invertien el seu potencial humà, i no d'una millora tecnològica suficient per a tota l'economia pagesa. En suma, el que va tenir lloc fou un augment de la producció; no de la productivitat. És així com s'entén que l'agricultura medieval fou extensiva i no intensiva. Aquest sistema, per la manca d'adobs o alternança de conreus, conduí inexorablement a l'esgotament de la terra, i aquest a la necessitat d'ampliar les terres de conreu a costa de prats, boscos i terres de menor qualitat.

"Anuario de Estudios Medievales", 29 (1999) 
Aquesta menor productivitat explica les nombroses peticions, des de finals del s. XIII, de reduccions en el pagament de censos. Però si es podria inferir que això desembocaria en una crisi de les rendes senyorials, la realitat és que aquesta no es farà prou notòria fins desprès de la pesta negra. Cal, doncs, pressuposar que una part important de les rendes que percebia el senyor terratinent provenien de la percepció dels drets senyorials.

Durant els anys de prosperitat, els propietaris aconseguiren sostreure parts importants dels excedents de la producció pagesa mercès a relacions contractuals, però també al règim feudal, que intervenia en qualsevol aspecte social mitjançant els drets senyorials coneguts com a mals usos i mitjançant els drets de ban que els permetia cobrar per la utilització del bosc o dels molins, entre altres.

Aquesta serà la raó per la qual una part dels senyors intentaran mantenir aquesta pressió senyorial, o fins i tot augmentar-la després de la pesta negra. La pressió sobre la remença fou una reacció natural en aquells senyors que temien l'èxode dels seus dependents a terres o senyorius millors. Però aquesta reacció, lluny de ser generalitzada, presentà variacions molt diferents segons la zona i segons el senyor, com queda il·lustrat en els mapes de la distribució dels remences a Catalunya, ben diferent al s. XIV del sorgit en el moment de la revolta. Si al s. XIII es viu una situació més o menys homogènia, amb pagesos remences a la Catalunya Nova i pagesos lliures a la Catalunya Vella (redimits per la compra de franqueses), cal preguntar-se la raó que motivaren les diverses evolucions posteriors. Una causa cal buscar-la en la variada situació econòmica en què es trobaven els diferents senyors, però sobretot en les diverses perspectives de futur que se'ls obrien. La situació social i jurídica de la població i l'adaptació del tipus contractual a les noves circumstàncies en són clares mostres.

A part de la inestabilitat social esmentada, la població catalana es veié sotmesa a la pressió financera protagonitzada per la monarquia. L'expansió mediterrània comportà grans sacrificis ja des de finals del s. XIII, sobretot a la població sotmesa al règim senyorial. La conquesta de Sicília tingué com a contrapartida el reconeixement de la remença per via legal. I serà Pere el Cerimoniós qui davant la falta de numerari propi va recórrer a la venda de les jurisdiccions reials als senyors de forma indiscriminada i amb notables abusos. Per una disposició reial, bona part de la població regida per la "llibertat" que oferia la monarquia, passà a estar sota la jurisdicció senyorial, amb totes les seves conseqüències. I no només va vendre la llibertat de les poblacions que estaven sota la seva "protecció", 
sinó també la d'aquelles altres poblacions que anteriorment havien estat capaces de reunir suficient moneda per comprar la seva llibertat. Aquesta situació perdurà des de meitats del $\mathrm{s}$. XIV fins a finals del XV, és a dir: tot i la presa de consciència que aquest no era el millor recurs, tots els monarques continuaren amb aquesta política, fet que conduí a la paradoxa que moltes poblacions havien de comprar la seva llibertat més d'una vegada ${ }^{1}$. De fet els contemporanis tenien plena consciència que una part important de la crisi en que es veié immers el Principat era deguda a la mala gestió de la monarquia i a la seva desmesurada ambició. Una bona mostra la proporciona la vila de Vilafranca del Penedès, la qual l'any 1473 presenta una queixa al rei després de ser empenyorada: "Primerament, lo principi de dit empenyorament, per rahó de estar tant carregada la vila, fonch per lo que los passats gastaren en fer servey a Nostre Señor Déu Omnipotent, y als sereníssims comptes de Barcelona y reys de Aragó, y a llur Pàtria, de ajudar-los ab diners, provisions...". Després de fer un recorregut per les dades històriques en les quals hagueren d'oferir-los ajut, afegeix: "E més, se empenyaren en la conquista de València, de Mallorca, Serdenya, Sicília, $\mathrm{y}$ en les guerres que tingueren los reys de Aragó en Castella, y en la conquesta de Nàpols... " Acabant: "E los anys de sterilitat, fams, y guerres $\mathrm{y}$ altros infortunios, la vila era la que provehia y lo govern de tot"2.

El problema remença i el de la compra-venda de les jurisdiccions podien arribar a coexistir, de tal forma que molts pagesos es trobaren en situacions econòmiques molt precàries pel fet d'haver de sufragar alhora la compra de la jurisdicció i l'alliberament de la remença. La pagesia estava totalment en mans dels seus senyors, els quals intentaren fer recaure sobre ells tant la solució a la crisi de les seves rendes i la del mateix sistema feudal. Es pot comprendre, per tant, l'estat d'indefensió en què es trobava la població i que, després de més d'un segle de suportar-lo, es desemboqués en una guerra civil.

\footnotetext{
'La compra venda de les jurisdiccions ha estat estudiat per Ma. Teresa Ferrer en el seu treball: "El Patrimoni Reial i la recuperació dels senyorius jurisdiccionals en els estats catalanoaragonesos a la fi dels s. XIV", "Anuario de Estudios Medievales", 7 (1971), pp. 351-491. Per la part geogràfica propera als Pirineus, ha estat presentat al segon Congrés Internacional d'Història dels Pirineus, Girona 1998 en el treball A. Serra: El lluisme de les jurisdiccions senyorials, un tema per a la reflexió, que està en premsa.

${ }^{2}$ El Llibre Verd de Vilafranca. Edició a cura de J. Vallès, J. Vidal, Ma C. Coll i J.M. BosCH, Barcelona 1992, pp. 527-531
} 
Mortaldats, pestes, terratrèmols, males collites anaren apareixent de forma cíclica durant els dos segles, de manera que tot plegat esgota una població prou conscient de la realitat. El 1431 la Universitat de Tàrrega exposa quina era la seva situació: "E après de algun temps, segons per disposició divinal, que no solament mortaldats, mes encara, secades e sterilitats de fruyts se seguiren en la terra... " I continua més endavant: "... atenent que continuants les dites morts de dos en dos anys e seguins-se secades e sterilitats de fruyts... ${ }^{3}$

La geografia, però, afectarà de manera diferent l'economia i la situació social diferenciada, dins el marc, és clar, d'una història global.

Així com la pesta negra i els posteriors rebrots afectaren per igual tota la geografia catalana, els terratrèmols de principis del XV marcaren unes diferències pel fet de produir-se en les regions del nord de Catalunya ${ }^{4}$.

A finals d'aquest segle els habitants de la vall d'Àger es mostraven molt preocupats per les pestes i per les adversitats meteorològiques (com ara fortes pedregades), de tal forma que els pahers i el batlle acordaren que tots els dissabtes del mes de maig del 1475 fossin festiu, igual que els diumenges, per tal de celebrar processons i precs a Déu que els protegís. Posteriorment, el 1492 esclatà una forta alarma entre els seus habitants fins al punt de muntar guàrdia davant l'entrada de la vila per tal d'impedir l'entrada d'aquelles persones que en els últims 30 dies haguessin estat en contacte amb llocs afectats per mortaldats ${ }^{5}$.

Lluites locals entre bàndols oposats de la petita noblesa provocaren inestabilitats socials i també grans prejudicis econòmics, per destruccions de les collites i dels mitjans de producció entre els dos fronts. Plagues de llagostes, terratrèmols, tot plegat frenà notablement la recuperació del país ja que aquests enfrontaments, tot i desenvolupar-se a nivell local, proliferaren arreu del país ${ }^{6}$. La conjunció d'aquests factors sumí Catalunya en una gran crisi.

\footnotetext{
${ }^{3}$ Doc. V del llibre Privilegis de Tàrrega ed. a càrrec de H. SARRET I PONS, 1982.

${ }^{4}$ Els terratrèmols de l'any 1427 afectà la Vall d'Amer, Olot St. Feliu de Pallerols, Osor, la vall de Llémena fins a Mieres. Mentre que el del 1428 afectà des de Puigcerdà fins a Lloret de Mar passant per la vall de Núria i el Collsacabra.

${ }^{5}$ Acords del 7 de maig del 1475 i del 1492 a F. FITÉ, Reculls d'Història de la Vall d'Àger. Període Antic i Medieval, Àger, 1985.

${ }^{6}$ Una primera aproximació al tema va ser presentat en el treball: A. SERRA, Anàlisis del conflicto y la guerra remensa en la zona de la "Muntanya" (Osona) a "VII Congreso de Historia Agraria", Baeza, 1995, pp.
} 
Es pot considerar, doncs, que per aquesta raó cal analitzar aquest fenomen a partir de peculiaritats geogràfiques $i$ històriques, que fan sorgir diferències entre els diferents indrets pel que fa als afectes de la crisi i també a les possibilitats de recuperació econòmica.

\section{LA PESTA NEgRa: \\ AVALUACIONS DEMOGRÀFIQUES \\ I REACCIONS IMMEDIATES DELS SENYORS}

Les mortaldats ocasionades per la pesta negra foren generalitzades per tot el país a l'igual que a tota Europa. Les mateixes comunitats eclesiàstiques aporten dades que reflecteixen aquesta situació. Testimonis concrets com els que apareixen enregistrats tant a la canònica de Sta. Ma. D'Olives a l'Empordà com al convent de Sta. Ma. de Ribes, mostren com en tots dos llocs moriren tots els membres de la comunitat menys un, el qual en el segon lloc s'erigí com a monjo prior ${ }^{7}$. D'altres estudis, com els que $\mathrm{s}^{\prime}$ han portat a terme tant a Osona com en la mateixa ciutat de $\mathrm{Vic}^{8}$, indiquen un mateix impacte tant entre la població concentrada com en la dispersa. A. Pladevall ha quantificat la disminució de la població d'Osona en els dos terços, a l'igual que al bisbat de Girona. Algunes dades de nuclis rurals són: de 85 focs entre masos i cases de la sagrera a Taradell, passaren a 36 masos i 6 cases. A Viladrau, de 87masos i 4 o 5 cases passaren a un total de 28 , a finals del s. XV. P. Pagès ha pogut constatar un fet social molt interessant a la Vall d'En Bas: "Després de la fatídica pesta del 1348 i anys següents moltes nissagues restaren interrompudes perquè llurs hereus amb la seva prole foren víctimes del contagi i molts masos es convertiren en rònecs; però altres foren establerts pels senyors alodials sense que els descendents dels anteriors emfiteutes poguessin tenir continuïtat en la successió per haver mort; i així d'aquelles noves nissagues mitjançant la descendència d'hereu en hereu, moltes han arribat fins als nostres dies, sense que tinguessin res

'L.G. Constans, Bañolas, Ajuntament de Banyoles, 1951, p. 98. i P. VILAR, Catalunya dins l'Espanya moderna, I, Barcelona, Ed. 62, 1981, pp. 197-199.

${ }^{8} \mathrm{~A}$. PLAdeVAll, La disminució de poblament a la Plana de Vic a mitjans del S. XIV, a "Ausa", IV (1961-63). En relació al poble de Taradell ha fet un anàlisi, J. P. CuviLliER, Una societat en crisi: la sagrera, la parròquia $i$ el castell de Taradell després de la pesta negra, 1352-1363, a "Ausa" (1971), pp. 227-241. 
a veure amb els que abans de la pesta ocuparen el mas"9. Un exemple contundent de la mortaldat d'aquesta zona és la parròquia de Sant Joan de Balbs, que, amb 23 masos comptats a la primera meitat del s. XIV, quedà deshabitat per les pestes del s. XV. Posteriorment al s. XVI se n'hagueren recuperat 6.

Segons les dades aportades per Robert-Henri Bautier, obtingudes a partir d'un estudi sobre el registre de les defuncions de l'església a la ciutat de Vic, la gran pesta del 1348 fou: "surtout une longue peste: de mai 1348 au début de $1352^{\prime \prime}$. Durant aquests anys, l'autor ha calculat que entre els mesos de maig, juny i juliol moriren 795 persones. Descomptant les 25 o 30 morts que solien tenir lloc en aquests mesos d'un any normal, dedueix que es passà a una mitjana de 60 morts mensuals degudes directament a la pesta, tot i no tenir registrades les defuncions dels jueus, ni dels nadons els quals no es feien constar en els registres eclesiàstics. El treball continua avaluant les morts produïdes pels rebrots de la pesta que de forma cíclica repareixia: el 1362 i el 1371, és a dir gairebé cada 10 anys. Les morts de l'any 1362 foren les registrades per un any normal multiplicades per 7 . En cada una d'aquestes epidèmies els afectats variaren. A l'igual com ocorregué a Girona la pesta del 1348 foren "les grans mortaldats"; les del 1362 "les mortaldats dels infants" i les del 1371 foren "les dels mitjans" "1, es a dir que anà afectant a cada generació.

Les dades aportades per algunes ciutats a partir dels censos sobre la seva població al llarg d'aquests segles permeten fer una valoració general. Així Terrassa, per posar un exemple, presenta una corba del descens de la població a partir de les dades aportades pels fogatges. En el de l'any 1359 Terrassa comptava amb 130 focs, mentre que el 1455 en tenia 77, el 1457 eren 69 i el 1483, després de la guerra, solament en quedaven $42^{12}$.

Ara bé segons S. Cardús, la causa d'aquest despoblament de Terrassa no foren solament les mortaldats "...principalment perquè havia

${ }^{9} \mathrm{~J}$. PAGĖS, Els Senyorius alodials en el vescomtat de Bas a la baixa edat mitjana, Olot, 1992, vol. 2, p. 543.

${ }^{10}$ Robert-Henri BAUTIER, Un nouvel ensemble documentaire pour l'histoire des pestes du XV" siècle: l'exemple de la ville de Vic en Catalogne, a "Ausa", XIV (1990), p. 40.

"R.H. BAUTIER, Un nouvel, op. cit. p. 49.

${ }^{12}$ S. CARdús, Terrassa Medieval. Visió històrica, Terrassa, Ed. Tallers gràtics Joan Morral, 1960, p. 113. Arxiu Històric de Terrassa, Llibre de Prvilegis, fol. 24, citat per S. CARDÚS, op. cit. nota n. 10 . 
estat venuda diverses vegades pel rei Pere i per moltes altres causes (sense oblidar la pesta negra i la costosa reconstrucció de les fortificacions) que desprès sobrevingueren, per la qual cosa la municipalitat es trobava fortament endeutada. Això feu que la major part dels habitants abandonessin les seves llars $\mathrm{i}$ es busquessin altres mitjans de vida,: '... maiorem partem hominum dicte Universitatis lares et habitationes propias desere et aliunde querere vitam suam'." El mateix es pot dir respecte a Vilafranca.

En el món rural es fa difícil fer valoracions exactes ja que molta gent efectuà desplaçaments tant entre el mateix àmbit rural com a la ciutat, i a la inversa, tal com queda reflectit en la documentació. La informació concreta que aporta un registre del Collsacabra sense identificar (tot i que es dedueix que es tracta d'un escrit fet per un eclesiàstic del lloc de Sant Andreu de la Vola) indica una mortaldat molt considerable ${ }^{13}$. El registre es refereix al mes de juliol del 1348 i comptabilitza la mortaldat dia per dia. Tot i que sempre s'especifica de quin mas era el difunt, en alguna ocasió afegeix que alguns d'ells són de Vic, fet que faria pensar en el moviment de població des de Vic, centre urbà, al món rural ${ }^{14}$. El nombre total de les morts que enregistra aquest document és de 178, repartits entre els 31 dies, essent el més freqüent el nombre de 7 morts diaris però arribant als $13 \mathrm{com}$ a xifra més alta.

El més característic d'aquesta crisi demogràfica foren les reincidències de les epidèmies, com també la contribució d'altres fenòmens destructors com les plagues, terratrèmols i la mateixa guerra, que anaren minant una població que no tenia oportunitat de refer-se i que arribà a a finals del s. XV en franca disminución ${ }^{15}$.

Aquestes mortaldats tenen una clara incidència en el despoblament i abandonament tant de masos com de petits nuclis rurals despoblats a la zona oest de Catalunya i masos rònecs a l'est.

\footnotetext{
${ }^{13}$ Aquesta informació és deguda a la recopilació documental que feu el sacerdot $\mathrm{Mn}$. I. Torredeflot de l'arxiu de la parròquia de Santa Maria de Corcó i publicada en la revista setmanal "Setmanari Català" de Manresa durant els anys 1892-1894.

${ }^{14}$ L'estudi de R.H. Bautier assenyala que la mortaldat es donà primer a la vila de Vic. Però en canvi considera que al mon rural l'impacte no fou totalment estès fins el 1350 en contraposició a la informació que dona aquest document.

${ }^{15}$ Una anàlisi global a nivell de Catalunya de la demografia de l'època ha estat publicada per J. NADAL i E. GIRALT, La population catalana de 1533 a 1717. Facteurs de son développement, París, 1961.
} 
Respecte als despoblats, són molt interessants els documents procedents del vescomtat de Castellbò ${ }^{16}$ dels últims anys del s. XV. Al capbreu de l'any 1493-1494 hi figura un escrit signat el 1443 pel mateix vescomte, on reconeix que: "... eren grandement despoblats, tant per rason de mortalitats cum per las guerres et caresties que són stades en lo dit vescomtat, per les quoaus causes ni poden pagar les questes e autres carchs et rendes en què són tenguts pagar a nós, et que dejà trops se'n foren anats en autres parts e terres on los bolen far bon acolliment... ". Més endavant continua amb la mateixa reflexió "... les dites valls, castells e lochs ésser grandement dirruïts et disminuïts de gens et bens així que per los dits cònsols e prohomens nos és stat expaussat, e que los tots o partida d'aquests se volen partir de aquí et anar poblar en autres parts fore nostre senyorie..." ${ }^{17}$. Així doncs, en aquest cas la crisi és anterior a la pesta i la supera.

En aquest capbreu es pot copsar el despoblament total de poblats i l'escassa presència d'habitants en els restants ${ }^{18}$.

Així a la Vall de Carbó "tot el lloc és rònech e deshabitat e no hi sta negu" així com a Castellpoll, Boxidera Colomera de la Serra el del Camp i el Caselles mentre que només hi queda 1 foc al lloc d'Anell, Favà l'Oliva de Carbó i l'Amella, 2 focs a Puy, Ares, Pujal, Senyús,3 a Carbó, 4 a Fontanet i 5 al lloc del Vilar. Per tant a la Vall de Carbó solament es mantenen 24 focs.

A la batllia de Sallent hi ha els llocs de Galeda, Pinyes i Carreu de Gavarra deshabitats. A Montanicell queden 5 masos i Funollet de masos en queden 2.

Mentre que el nucli de Castellbò amb 65 caps de casa i 54 a la vall es mantenen encara bastant poblats. Respecte a l'impacte exacte del que va representar aquest despoblament és difícil d'avaluar ja que molts llocs, tot

\footnotetext{
${ }^{16}$ Una part important d'aquesta documentació ha estat transcrita per Cebrià Baraut destacant l'obra recopilada l'any 1519 pel notari Pere Tragó: "Spill manifest de totes les coses del vescomtat de Castellbò" i publicada el 1982. Tal com assenyala C. Baraut, entre les fonts utilitzades pel notari ocupen el primer lloc els dos "Capbreus" del vescomtat dels anys 14931494 i 1602-1606. D'aquests dos, el primer és molt útil per analitzar tant l'impacte de la disminució demogràfica que suposà la pesta $\mathrm{i}$ les successives crisis com la situació jurídica $\mathrm{i}$ social en aquesta zona a finals de l'edat mitjana.

${ }^{17}$ Capbreu del vescomtat de Castellbó, 1493-1494 transcrit i publicat per C. BARAUT, doc. n. 10 de l'Apèndix II del ja mencionat "Spill", Societat Cultural Urgel-litana, La Seu d'Urgell, 1982. cit.

${ }^{18}$ Capbreu del vescomtat de Castellbó, 1493-1494, transcrit i publicat per C. BARAuT, op.
} 
i no estar totalment despoblats, solament hi resten un parell de famílies, sense que es pugui deduir el que representa, al no tenir una referència exacte de la població en una etapa anterior. Tot i així, es comprova com la baixada demogràfica fou molt més pronunciada en el poblament dispers, quedant molts llocs solament un parell de famílies, essent el cas més poblat el de 5 famílies. Aquests resultats recolzen les conclusions a que arriben autors que han estudiat l'impacte de la pesta negra per a aquestes zones i que consideren que fou més important al llarg del s. $\mathrm{XV}^{19}$.

\section{Els masos rònecs}

Referències directes a masos rònecs es poden aconseguir a partir d'un seguiment de diversos anys dels registres notarials de parròquies concretes, com les que s'han exposat de Taradell o Torellò, on Mn. F. Solà comptabilitzà un mínim de 14 masos rònecs entre tots els masos més coneguts $^{20}$.

És difícil poder aconseguir la quantitat exacta dels masos abandonats a causa de la pesta negra ${ }^{21}$, per l'absència de cap registre. Tampoc en els capbreus, encara que corresponguin als anys propers a aquest esdeveniment, s'hi fan constar els masos abandonats si no han estat incorporats a d'altres masos o reutilitzades les seves terres. Per tant, sempre en pot quedar un percentatge sense registrar. Però no es poden menystenir aquells capbreus que es realitzaren per a redimir algunes càrregues als pagesos que o bé tenien les terres d'aquests masos o d'aquells que, tot $i$ haver-los abandonat, mantenien els seus drets. Un bon exemple d'aquests capbreus és el que ordenà el vescomte de Cabrera a un oficial seu i a dos prohoms dels llocs, per tal que actualitzessin l'estat de les terres i masos del seu senyoriu en

${ }^{19}$ I. PUIG i M. DURAN, La crisi demogràfica de la baixa edat mitjana i el règim senyorial en el Pirineu català: La Baronia d' Erill el 1393, "Urgellia", 6 (1983), pp. 387-400, i A. VILARó, La pesta Negra, el 1348, a la Seu d' Urgell, "Urgellia", 8 (1986-1987), pp. 271-302.

${ }^{20} \mathrm{Mn}$. F. SolÀ, Història de Torelló, Barcelona, 1947, pp. 295-297. L'autor no especifica l'any del recompte.

${ }^{21}$ Tot $\mathrm{i}$ que hi han testimonis de documents que en fan referència a la causa del seu despoblament com el document localitzat a St. Julià del Montseny on el 1368 consta que el mas Calvet, que pertanyia a la senyoria dels Cabrera, estava deshabitat i s'anava enderrocant com a consequència de la mortaldat de l'any 1348. O també el de l'any 1415 en el qual consta com al lloc del Pujol de Santa Maria de Pineda hi havia una terra que estava sense conrear per raó de les mortaldats i misèria dels darrers anys. Docs. 574 i 878 respectivament de J.M. PONS GURI, op. cit. 
diferents anys, reduint les prestacions o anul-lant els masos en aquells casos en què ja estaven derruïts. L'any 1377 se centrà en les seves possessions de la part d'Osona, mentre que les de la Vall d'en Bas foren comprovades l'any 1383. Aquest procés també es portà a terme a Tona l'any 1388 i a Sant Privat d'en Bas el 1401.

El capbreu de 1377 (procés que es repetí en anys posteriors, concretament el 1398) sobre les terres d'Osona es dirigí bàsicament a la zona del Collsacabra, on 8 masos foren declarats rònecs i 2 foren repartits. Del mateix Collsacabra, l'any 1379 es recopilà el capbreu del senyor del castell de Rupit i Fornils, en el qual, si bé cap mas no fou declarat rònec, es posa de relleu la possibilitat que de dos a quatre masos acabin en mans d'un sol emfiteuta, i que s'acumulin fins a 15 peces de terra diferents procedents de diversos masos. Així es pot considerar que uns 40 masos foren absorbits en uns $67 \mathrm{i}$ unes 236 peces de terra foren repartides entre 23 remences, a part de les dels seus masos i 124 entre 39 no remences ${ }^{22}$.

D'altres capbreus similars són el de Tona de l'any 1388 o el del monestir de Sant Joan de les Abadesses del 1401, que van ser recopilats per reglamentar la posada en conreu de terres que havien format part de masos (el de Sant Joan) o la reducció de censos d'aquelles terres el rendiment de les qual s'havia demostrat insuficient (el de Tona).

Amb el mas deshabitat i en ruïnes, s'imposava la renúncia del dret d'host i cavalcada: a la Garrotxa, en la capbrevació de l'any 1383, en consten un mínim de 15 casos. Aquest procés continua en anys posteriors, fins i tot amb el permís per el derruïment del mas per part del senyor, com succeí el 1389, després de crides infructuoses per poder-lo recuperar. Tal com es pot veure, en aquestes zones l'impacte fou notable. A finals del s. XIV, hi havia un mínim de 40 masos deshabitats. Alguns d'ells, cap a finals del s. XV o principis del XVI, s'aconseguiren recuperar, com el mas de Bolós, però d'altres, com el mas Vila Sobirà, després de l'intent de reaprofitar-lo per a vinyes, acabà derruït també a principis del $\mathrm{XVI}^{23}$.

El 1394, el monestir de Sant Privat féu un capbreu per regular la situació dels seus dependents, en el qual es testimonia una posició molt dura,

\footnotetext{
${ }^{22}$ Aquests resultats han estat elaborats en el treball, A. SERrA, Economía y sociedad a lo largo del s. XIV en la Cataluña Central: Efectos de la peste negra a "Señorio y feudalismo en la Península Ibérica ss. XII-XIX", Zaragoza, 1993, vol III, pp. 449-472.

${ }^{23} \mathrm{~J}$. PAGÈs, Els senyorius alodials en el vescomtat de Bas a la baixa edat mitjana, 2 vols., Olot, 1992.
} 
obligats com estaven a la remença i a dos mals usos, així com a la renúncia a fugir a altres llocs o ciutats. En canvi, un capbreu posterior del 1401, reconeixia l'estat de les terres. ${ }^{24}$.

Per la seva part, el monestir de Santa Maria d'Amer, el 1352, en les seves possessions a la Vall d'Amer, hi figuraven 17 masos rònecs, 3 a Sant Climent de Mer, 2 a Granollers, Vidreres, etc. ${ }^{25}$.

Per obtenir una quantificació aproximada dels masos rònecs poden ser útils algunes fonts indirectes, com les compra-vendes o la reutilització de les seves terres. A Provençana, una zona propera a Barcelona, on la pesta ocasionà un lleuger impacte en el desenvolupament econòmic de la zona, les referències als masos rònecs són diverses. Així, el 1358 es produí una concessió de terres en un lloc on anteriorment figurava el mas d'Arnau Ferrer; el mateix ocorregué el 1381 en el lloc on abans estava situat el mas Gual. En alguns documents es fa referència explícita a l'aspecte del mas, com en la venda d'una peça de terra el 1375 , en què el mas d'A. Guerau consta com a derruït, o el 1386, en què el mas Margalet figura com a inculte. Dades semblants es repeteixen en el s. XV. En resum, en aquesta documentació es poden comptabilitzar un mínim de 10 masos rònecs que desaparegueren com a tals i foren reaprofitats com a terres, sense comptar els masos que foren totalment abandonats. Igualment propera a aquesta zona com a Cornellà de Llobregat, entre el 1353 al 1418 es comptabilitzaren 13 masos rònecs ${ }^{26}$.

A la zona de Calella i d'Arenys de Mar o fins i tot a la part de la Selva, és a dir, una zona prou àmplia formada per part de costa i d'interior, el fenomen dels masos abandonats es concentra més en el s. XV que en el s. XIV. La presa de consciència dels contemporanis del fet que aquells masos ja no tornarien a estar poblats, prengué carta de naturalesa en anys més tardans que no a Osona o La Garrotxa ${ }^{27}$.

\footnotetext{
${ }^{24}$ J. PAGÈs, Els senyorius alodials, op. cit. pp. 259-260.

${ }^{25}$ Arxiu Episcopal de Vic. Secció capbreus. Capbreu del vescomte de Cabrera.

${ }^{26} \mathrm{~J}$. CodINA, Els pagesos de Provençana (984-1807). Societat i economia a l'Hospitalet preindustrial, Barcelona, Publicacions de l'Abadia de Montserrat, 1987, vol. I; i Joan FERNÁNDEZ Trabal i Josep Fernández TRABal, La societat agrària de Cornellà a l'Edat Mitja: Pagesos i propietaris (980-1400) dins Cornellà de Llobregat: Estudis d' Història, Cornellà de Llobregat, 1987.

${ }^{27}$ Certament cal considerar que aquests masos que apareixen com a rònecs en el $\mathrm{s}$. XV, alguns ja ho eren en el s. XIV. Així es pot comprovar amb el mas Dolç, de Pineda. El 1435 consta com a rònec $\mathrm{i}$ amb el mas derruït de tal forma que el senyor dona permís per a derruir-lo
} 
En la part de Calella, des del 1429 quan es donà la venda d'una terra, on abans havia hagut el mas de Bertran de Capaspre, fins el 1445 es reconeixen 4 masos o bordes derruïdes. $\mathrm{Al}$ mateix temps es redueixen les tasques que s'han de pagar per les terres de masos abandonats que es mantenen treballades. I en els registres de l'arxiu d'Arenys se'n comptabilitzen un mínim de 10 entre el 1350 i 1450 . Algun d'ells consten com a rònecs com el Tudó o el Conill, mentre que d' altres es constata el repartiment de les terres, com el Dolç.

Cal tenir present que entre el 1384-88 la part de Girona es veié afectada pels enfrontaments entre la monarquia i el comte d'Empúries i el $1390 \mathrm{amb}$ el comte d'Armanyac.

És molt interessant el document redactat a Peralada l'any 1448, en el qual Margarida, muller de Jofre de Cruilles i hereva dels cavallers Bernat i Raimon de Limós, atorga poders a Antoni Segaleres. Entre les clàusules cal destacar el paràgraf següent: "... ad stabiliendum seu emphiteosim dandum per me et nomine meo omnis et singulas terras, honores et possessiones, domus, mansos et hospicia mea qui sunt steriles et ronegas... ". El mateix contingut es repeteix el 1452 en l'assignació de poders a Gaspar de la Via, ciutadà de Girona, com a tutor del menor Joan de Rasset ${ }^{28}$.

El 1426 i 1427 , Osona i la Garrotxa van presenciar uns forts terratrèmols, que empitjoraren la situació al s. XV. A la part d'Olot, el testimoniatge més colpidor d'aquest terratrèmol fou la construcció d'un poblament a partir de barraques situades a la part exterior del nucli de poblament que quedà derruït.

Montsalvatge recopilà els efectes que provocà entre els contemporanis. El del 1426 afectà especialment Olot, Castellfollit, Ridaura, Santa Pau, el Mallol "...e tots els masos de Bas, hoc encara, que mudà un bosch de verns, que era rost, en un bon tret de metres". El de l'any 1427 afectà Castellfollit, Olot, la vall de Bianya, Camprodon, Osor, Anglès, Mieres i Amer. L'impacte que suposà la destrucció del monestir d'Amer fou enregistrat per Villanueva: "He en aquella jornada matexa se féu un gran

\footnotetext{
totalment. Anteriorment en l'any 1397 es pot observar el repartiment de les terres que pertanyien al mas Dolç. Doc. 964 i 763 respectivament de J. Ma ${ }^{\mathbf{a}}$. PONS I GURI, Inventari dels pergamins de l'Arxiu Històric "Fidel Fita" d'Arenys de Mar, Barcelona, Generalitat de Catalunya, 1984.

${ }^{28}$ Docs. 4 i 11 de l'apèndix documental de S. SOBREQUÉS VIDAL, Jofre VIII de Rocabertí, señor de Peralada y el ocaso de la Edad Media en el Alto Ampurdán, Palau de Perelada, 1955.
} 
trench de la terre per les muntanyes de Bas, e de Hostoles en la part de ponent, qui tenia un larch en torn VII leguas..."29. Això va tenir les lògiques conseqüències en l'augment de masos rònecs: a la vall d'Hòstoles, en una venda de 17 masos enregistrada en l'any 1424, 6 eren declarats rònecs, xifra que representa un percentatge del $35 \%$.

Aquests terratrèmols es feren sentir igualment en la part del bisbat de Vic, on edificis singulars, com la torre del campanar de Santa Maria de l'Estany, no van aguantar en peu.

A Osona, en concret de la part de la plana de Vic a Sant Hipòlit de Voltregà, en el capbreu de l'any 1444, d'un total de 52 masos 10 són declarats rònecs $i$ en un estat de destrucció tal que obligà a repartir-ne les terres. Aquests 10 masos s'anaren convertint en rònecs a partir de la dècada dels 60 del s. XIV. D'una segona etapa, del 1437, se'n comptabilitzen 13 masos més, el quals, sense ser reconeguts com a rònecs, foren distribuits entre 4 famílies. Així el total és que de 52 masos, 23 havien estat abandonats.

Tal com queda de manifest, no tots aquests despoblaments foren deguts a la mort dels seus habitants, sinó que es van veure afectats per intenses migracions: cap a ciutats, d'unes ciutats a altres, d'un senyoriu que oferia dures condiciones a un que oferís millors tractes, o també a llocs amb perspectives d'una millora econòmica; de Sant Hipòlit o Sta. Ma. de Corcó a Barcelona o de les terres de la baronia de Pinós i Mataplana a la Cerdanya $^{30}$.

Altres masos quedaven buits a causa de les dificultats financeres dels pagesos, que es veien obligats a malvendre els masos per fer front als seus propis deutes o els de les persones que els seus familiars havien mort o que havien emigrat. Aquest és el cas de l'Elisenda Aulet de Sant Iscle de Vallalta, qui l'any 1350 va vendre el mas Aulet per satisfer els deutes del seu oncle ${ }^{31}$. Al vescomtat de Bas l'any 1356 es vengueren la cabana de Busquets de Vall, el mas Campdepuig, o el mas $\mathrm{Clot}^{32}$, per tal de que el

\footnotetext{
${ }^{29}$ Aquestes dues referències han estat recollides per J. CAMPS I ARBOIX, Verntallat, Barcelona, 1955, pp. 67-68.

${ }^{30} \mathrm{M}$. BERTHE, en el seu treball Famines et epidémies dans les campagnes navarraisses à la fin du Moyen Âge, París, 1984, ha aconseguit demostrar aquest desplaçament al poder seguir el rastre d'un grup de població al llarg d'uns anys.

31 Doc. 446 de J. Ma. Pons Guri: "Inventari...."op. cit.

32J. PAGÈs, Els senyoris alodials, op. cit., vol I p. 62; vol. II, pp. 174 i 525.
} 
senyor pogués cobrar els censos que havia deixat de percebre. En aquests mateixos anys es repetí aquest tipus d'actuacions a Mataró, on es vengueren vuit masos per les mateixes raons ${ }^{33}$.

Altres mostres de la difícil situació que havien de suportar els pagesos són el retorn de masos davant la incapacitat de pagar els censos estipulats, tant per falta de mà d'obra com per l'estat de la terra. Aquest fenomen, molt més freqüent entre les dones, és generalitzat a tota la geografia catalana, com al Ripollès, Osona, el Maresme o la Garrotxa ${ }^{34}$.

\section{Reaccions senyorials}

Una anàlisi comparativa entre diferents senyors i diferents zones ens indica que no hi ha un patró comú de conducta. En una mateixa zona, l'actuació de dos senyors pot ser la contrària l'una de l'altra, com queda de manifest al Collsacabra. En una zona muntanyosa com aquesta, la reacció entre el senyor de Cabrera i el de Rupit, Aussies de Cruilles, fou ben diferent: mentre el primer reconeix la situació i renuncia als drets que tenia sobre masos, ara rònecs $\mathrm{i}$ sense habitants, $\mathrm{i}$ fins $\mathrm{i}$ tot redueix censos en aquelles terres que s'han comprovat infructíferes, el de Rupit reacciona amb una pressió més intensa i imposa als pagesos la remença i els cinc mals usos. Segurament aquesta fou la raó per la qual el castell de Rupit fou un focus important en la revolta remença. La causa d'aquest comportament tan divers cal atribuir-la a les diferents possibilitats de recuperació a la crisi que podien tenir els dos senyors.

\footnotetext{
${ }^{33}$ C. CuAdrada, El Maresme Medieval: Hàbitat, Economia i Societat, ss. X-XIV, Mataró, 1988, p. 293.

${ }^{34}$ Com a exemples concrets, tenim el retorn del seu mas per part de Sibila, hereva del mas Surell del terme de Santa Maria de Palautordera $\mathrm{i}$ casada amb Bernat Gras de Cànoves al monestir de Sant Cugat. Doc. 440 de J.M. PONS GuRI, Inventari, op. cit. Així mateix Gueralda de Sta. Maria d'Scales del seu mas Planes el 1358 o el de Saurina, que pertanyen al monestir de Camprodon el 1362, docs. 1510 F. MonTSALVATGE, El Condado de Besalú, II o el de Caterina al senyor de Sant Hipòit. El 1377 fou restituït el mas Vilar de Sant Vicens de Torelló al vescomte de Cabrera, per la incapacitat de pagar els censos. La restitució fou feta per Margarita. Capbreu del vescomtat de Cabrera... 175 v. Caterina de Sant Hipòlit, també retornà el seu mas al senyor per les mateixes raons. Arxiu Episcopal de Vic, Secció Capbreus. També al monestir d'Amer, el 1357 se li retornaren un mas per la incapacitat de poder pagar les rendes. Doc. 1469 de F. MonTSAlvatge, op. cit.
} 

senyorials

A partir d'aquest plantejament, cal observar les diferents actituds

Una de les reaccions senyorials mes impactants fou la de prohibir el moviment de les persones per tal d'impedir-los que abandonessin els dominis dels senyors. El cas més conegut és el del senyor de Pinós i Mataplana, que imposava multes de fins a $10 \mathrm{ll}$., és a dir $250 \mathrm{~s}$., el $1356 \mathrm{i} \mathrm{ja} \mathrm{el} \mathrm{doble,} 500$ s., dos anys més tard. Aquest augment s'explicaria si la primera quantitat no va donar els fruits esperats, i de fet així es constata a través del nomenament, l'any 1357, de Ramon Fortuny i Ramon Saig com a procuradors especials per tal que fessin tornar els homes i dones propis que havien fugit a la Cerdanya. I com que el senyor deuria veure difícil aconseguir-ho, procurà no donar-tot per perdut i poder cobrar-ne almenys la remença ${ }^{35}$. La pressió senyorial marcarà la vida a pagès d'aquests segles, i els consegüents intents de fugida no deixaran de ser-hi presents. Al s. XV, en concret el 1418, en l'acta de possessió del castell de Requesens a l'Empordà, Dalmau, vescomte de Rocabertí, assenyalà que: "... Encara més mana lo dit molt noble bescompte de Rocabertí, Sr... de Requesens, a tothom... , que no i haje nengun ni nenguna qui gos passar los termens del... castell..., sots pena de penjar a cascún, sens tota mercè" ${ }^{36}$. Igualment simptomàtic és el pacte a què arribaren l'any 1354 el senyor de Mataplana i el pagès del mas Serra de Vallfogona, pel qual el senyor li atorgava permís durant 15 dies a l'any per poder sortir de la seva jurisdicción ${ }^{37}$.

En general els impediments que els senyors posaven als desplaçaments dels habitants fora dels seus senyorius, desapareixien si el que pretenien era canviar de lloc dins de la seva jurisdicció. Aquest és el cas del senyor Bernat, vescomte de Cabrera, el qual el 1389 dóna permís a Ramon de Calm de Sant Esteve de Bas per poder desmuntar la masoveria i emportar-se'l, pedra per pedra, a un lloc més adient, dins els termes de la pròpia masoveria. Deu anys més tard, el 1399, el mateix vescomte dóna permís a Antoni de Vilamala, de la mateixa parròquia de Sant Esteve de Bas,

\footnotetext{
${ }^{35} \mathrm{Cal}$ tenir present que el reconeixement de ser home propi i sòlid no implicava la remença. El document és de J. SERRA VILARó, Baronies de Pinós i Mataplana, Barcelona, Ed. Balmes, 1947, Llibre segon, pp. 342-343.

${ }^{36}$ Doc. n. 174 de l'apèndix documental de M. Golobardes, Els Remences, Palau de Peralada, 1970, vol. II

${ }^{37}$ J. SERra Vilaró, Baronies, op. cit. p. 338
} 
per tal d'enderrocar la masoveria de Causidor, situada en la mateixa parròquia, i poder portar les pedres, teules i fusta a un lloc de lliure elección ${ }^{38}$.

En canvi l'esmentat senyor Pere de Pinós cobrà $160 \mathrm{~s}$. d'un home que estava sota el seu domini pel fet de viure a Saldes i establir-se a Bagà, que també formava part del seu domini ${ }^{39}$. En sentit contrari, pot ser el mateix senyor el que posi la condició que el remença vagi a viure allà on decideixi el senyor, tal com s'ha vist anteriorment.

De fet, algun senyor fins i tot imposa una completa disponibilitat de les persones remences. En la part de Torellò (Osona), F. Solà constata com en alguns documents de reconeixement de servitud a partir de la pesta negra apareix una nova clàusula: "No obstant, prometo que sempre que vulgueu aniré al lloc on vos preferireu; de dia i de nit, amb sols el requeriment escrit, particular o públic del nunci, o mitjançant avís amb deu dies d'anticipació". En la mateixa línia, però ja entrant més en detalls, el reconeixement de servitud de l'any 1377 de Francesc Martí al vescomte de Rocabertí inclogué la promesa de traslladar-se al domicili de Santa Llogaria si així ho requeria el senyor ${ }^{40}$.

Si bé aquests casos mostren uns pactes particulars, els senyors buscaren fórmules més generalitzades per aconseguir frenar la fugida dels pagesos dependents.

Alguns autors, com Serra Vilaró o Gaspar Feliu han constatat un augment ${ }^{41}$ de preus. De fet preus com els 150 sous que pagà Sança, la qual era filla de Bernat i Basetriu i no consta com a casada, ni vídua al cavaller Pere de Maçanet el $1349^{42}$ o els 200 , o 250 que apareixen després de la pesta negra en llocs tant distants com el Berguedà, Osona, el Maresme, o La Garrotxa, mostra una realitat en la utilització d'aquest recurs.

A Tavertet, els preus de les remissions d'abans de la pesta negra oscil·len entre els 15 i $20 \mathrm{~s}$, amb uns màxims de 60 o $80 \mathrm{~s}$. En canvi,

\footnotetext{
${ }^{38}$ J. PAGĖS, Els senyorius, op. cit., I pp. 213 i 223 respectivament.

${ }^{39} \mathrm{~J}$. PAGÈs, Els senyorius alodials en el vescomtat de Bas. op. cit. J. SERRA I VILARÓ, Baronies, op. cit. p. 334.

${ }^{40} \mathrm{~F}$. SOLÀ, Torelló, p. 190; i doc. 155 de l'apèndix documental de M. GolOBARDES, Els remences, op. cit. respectivament.

${ }^{41}$ J. SerRa VIlaró, Baronies, op. cit., II, pp. 329-334 i G. Feliu, El pes econòmic de la remença $i$ els mals usos a "Anuario de Estudios Medievales", 22 (Barcelona 1992).

${ }^{42}$ Doc. 434 de J. Ma . PONS GURI, Inventari, op. cit.
} 
després es disparen fins arribar als 45 fl. (11 s. el florí), que reclama Roger, el senyor de Malla, el 1398 a R. Coma de Tavertet ${ }^{43}$, que no es pot considerar una persona rica. O les $11 \mathrm{ll}$. o sigui $220 \mathrm{~s}$. que els monestirs de Santa Cecília i Santa Maria de Montserrat i de San Miquel del Fai demanaren a Guillem Ponç, fill de Bernat Ponç i Margarida, de la parròquia de Sant Joan de Campins el 1388 així com les 12 ll., és a dir 240 s. que el donzell de Castelló d' Empúries feu pagar a Joan Dalmau el 1455. En aquest cas, el pagament el fa l' esmentat Joan el qual tot i ser fill del mas, ara viu a Badalona, però el mas tot i estar derruït encara mantenia els drets de la remença, així com els mals usos de la cogúcia, intèstia i eixòrquia. Es a dir que tot $i$ viure en una ciutat li cal redimir-se d'un mas derruït, i per tant a un preu molt alt $^{44}$.

Tot i que aquesta opció no fou generalitzada, donat que la Pia Almoina de Girona no hi va recórrer ${ }^{45}$, no es pot negar que fou un recurs més. L'interès del senyor rau a tenir els masos habitats per poder-ne cobrar els censos i prestacions. En aquesta línia es pot entendre l'actitud d'aquells senyors que optaren per la via contrària, per oferir bones condicions i fins i tot renunciar a parts de les servituds, com el cas del vescomte de Cabrera ja vist.

Un altre recurs és el d'estipular, en els documents de reconeixement de servitud, la renúncia al dret de refugiar-se a la ciutat, en un altre castell o un altre senyor. Aquesta fórmula s'aplicà de forma estesa a partir de la pesta negra sobretot en la zona de la "Muntanya"46 i en alguna part d'Osona com a Torelló, on ja s'utilitzava a principis del s. XIV. Tot i que la fórmula és reiterativa en tots els documents, un de l'any 1353 aclareix el perquè d'aquesta fórmula: "I prometo a vos i als vostres, que seré bo, fidel i legal, així com un bon vassall deu ser al seu senyor natural; i no entraré

\footnotetext{
${ }^{43} \mathrm{AEV}$, Secció Capbreus. Capbreu dels vescomtes de Cabrera, 130r.

${ }^{44}$ Doc 772 de PONS GuRI, Inventari, op. cit; i doc. 489 de J. Ma PONS GURI i J. RODRÍGUEZ BLANCO, Inventari dels pergamins de l'Arxiu Històric Municipal de Calella, Barcelona, Fundació Noguera, 1990.

${ }^{45} \mathrm{R}$. LlUCH, Remences redimits. El domini de l'Almoina del pa de la Seu de Girona, a "Anuario de Estudios Medievales", $27 / 2$ (Barcelona, 1997), pp. 869-902.

${ }^{46}$ 'entén per la zona de la "Muntanya" la regió de les Guilleries. Aquest terme geogràfic era l'emprat en l'època.
} 
en cap castell, ciutat o algun altre lloc de manera que vos i els vostres em pugueu perdre" ${ }^{17}$.

Una altra condició fou el pacte de redempció, sempre i quan el senyor ho volgués. Així es pot entendre com famílies tant rellevants socialment i econòmica com els Avenc, Casasses o Ententes al Collsacabra; els Pujol a Sant Hipòlit de Voltregà, o els Tria a Arenys es mantingueren remences. En aquestes zones és obvi que al senyor no li cal augmentar el preu. Alguns fins i tot pacten la remissió de la remença amb la condició de tenir el mas afocat ${ }^{48}$. Per tant, no són els diners de la remença l'objectiu prioritari dels senyors sinó mantenir els masos habitats i conreats per poder cobrar els censos i drets.

Un altre exemple mostra aquest interès com el que protagonitza el senyor Bernat de Cabrera el 1392 el qual concedeix dos masos els Busquets de Dalt i el Busquets de Baix que havien quedat buits després de les mortaldats del 1348 en establiment emfitèutic, però amb la condició de mantenir afocat el mas que habiten ${ }^{49}$.

El més freqüent era que fos l'hereu el que estigués obligat a mantenir el mas afocat sense tenir la possibilitat de redimir-se, possibilitat de què sí gaudien els germans. Aquest és el cas del pagès que habita el mas Palau de Montagut, pertanyent al monestir de Sant Pere de Camprodon, el qual el 1363 fa una declaració de la seva situació jurídica davant del seu senyor i reconeix que ell, com a hereu, no es podrà redimir ${ }^{50}$. Aquesta mateixa situació es repeteix el 1433 en el mas Biosca, però amb més exigències sobre les condicions que ha de reunir l'hereu: "... heredem

\footnotetext{
${ }^{47} \mathrm{El}$ senyor és Jaume d'Aiguanegra i el pagès és Arnau de Comarravera de Joanetes. J. PAGĖs, op. cit., II, p. 64.

${ }^{48}$ Aquest és el cas de la masoveria de Pou propietat del priorat de Sant Corneli. El 1393 reconeixen que la dita masoveria està deshabitada des de les mortaldats del 1348 . I veient la dificultat que hi havia per trobar conreadors que s'avinguessin a complir amb la remença i que en canvi els seria més beneficiós tenir les terres treballades, l'estableixen a Guillem de Vedella commutant els drets senyorials per un pagament. J. PAGĖS, Els senyorius, op. cit., vol. II, p. 166.

${ }^{49}$ J. PAGĖS, Els senyorius, op. cit., II, p. 205. De fet aquesta situació no és nova. L'any 1327 es concordà l'establiment emfiteutic pel mas Viader de Sta. Coloma de Vinyoles per part del cavaller Mascó. Les condicions que imposà a la nova familia foren: que en el temps de 8 anys havien de construir dues cases en el pati del mas, tal com ja hi havien sigut. I que dintre de 10 anys havien de tenir un fill o filla $\mathrm{i}$ el facin home o dona propis. Arxiu de la Fundació Maurí de La Garriga, doc. n. 9.

${ }^{50}$ Doc. 1588 de F. MontSalvatge, Colección Diplomática del condado de Besalú, Olot, 1906, vol. II.
} 
hominem si fuerint masculi, vel feminam casu quo non sint masculi, ydoneum et suficientem non insensatum nec diformem...

$\mathrm{Si}$ aquestes eren les condicions imposades als hereus, cal suposar que les dones resistien millor les pestes o presentaven una major immunitat o que superaven en nombre als homes d'una mateixa família. La realitat és que a partir de l'anàlisi d'alguns capbreus s'observa una forta presència de dones com a hereves de masos. Segons el capbreu de Rupit del 1379 de 100 declarants, 32 eren dones, així com el de Tona del 1388, de 14 declarants, 4 eren dones (28,5\%); en el de Sant Joan de les Abadesses del 1401, de 26 n'eren 9 (34\%), i del castell d'Orís del 1442, de 30 capbrevats, 7 eren dones $(23 \%)^{52}$. Respecte a la part del Maresme, el percentatge desvirtuaria aquestes proporcions que s'han presentat, donat que no és un capbreu on figura el senyor útil, i en aquest cas gairebé un $90 \%$ dels documents són econòmics i per tant estan protagonitzats per homes. Però, en canvi es constata una gran presència femenina com en remissions, quan tant la senyora com la remença són dones; o la mort dels marits amb una gran activitat per part de les vídues, entre altres. Per tal d'interpretar correctament aquestes xifres, cal tenir en compte que perquè una noia passés a ser hereva era necessari que o bé no tingués cap més germà o que haguessin mort tots, tal com es pot comprovar en qualsevol testament, en què la noia anava després de tots els nois en la línia de successió.

La importància que van adquirir les dones en aquesta època es veu reflectida en el privilegi que se solia atorgar de redempció, sempre i quan fos per casar-se. L'interès es trobava en afavorir els matrimonis per tal de que tinguessin fills i així augmentar la població.

De la documentació recollida de Calella del Maresme, de 10 remissions comptabilitzades en el període comprès entre el 1350 i 1420 , solament 3 són de nois. En canvi, les remissions o franqueses en la remissió de noies per maridar-se queden documentades al Collsacabra, al Berguedà, o a la Vall d'en Bas. Tot i que alguns senyors imposaven preus lleugerament

\footnotetext{
51J. SERRA VILARÓ, Baronies, op. cit. p. 346 nota 3.

${ }^{52}$ Arxiu Episcopal de Vic, secció dels capbreus. L'estudi concret sobre l'impacte de les pestes del s. XIV a Vic de R. H. Bautier, abans esmentat indica que tant les mortaldats del 1348 com les del 1362 afectaren de forma molt notable el sexe masculí mentre que les de l'any 1371, més suau, la proporció presenta un equilibri entre els dos sexes. R.H. BAUTIER, Un nouvel, op. cit.
} 
diferents, foren respectats els habituals 2 s. 6 d. ${ }^{53}$, llevat a Calella o Arenys, on s'arribaren a reclamar des de 33 s. o 6 ll. (120 s.) a 8 florins (88 s.) a principis del XV per a noies que es reconeixien verges ${ }^{54}$. A la Vall d'en Bas, a part d'alguna remissió a $20 \mathrm{~s}$., es pot considerar que en general tots els senyors complien els $2 \mathrm{~s}$. $8 \mathrm{~d}$. per a les donzelles. El mateix es pot dir del vescomte de Cabrera i fins i tot del senyor de Rupit, el qual, tot i la seva pressió amb la imposició dels 5 mals usos i la remença, també participà de les franqueses a les noies per casar-se.

Alguns casos coneguts són el de Blanca, qui per redimir-se del benifet de Pineda el 1399 hagué de pagar $44 \mathrm{~s}^{55}$. Més sorprenents són els 150 s. del 1349 o els 100 s. que el 1368 el monestir de Sant Martí Sacosta de Girona imposà per la remissió de Margarida, la qual estava casada amb P. Eimeric de Sant Cabrià. Aquesta quantitat fou pagada la meitat pel seu pare i l'altra pel seu marit ${ }^{56}$.

\section{ANÀLISI DE LA CRISI SENYORIAL A TRAVÉS D'UNA FORMA CONTRACTUAL PECULIAR}

El tipus de contracte que a continuació s'analitzarà és el propi de l'establiment emfitèutic, però adaptat a les noves necessitats senyorials sorgides després de la pesta negra. La primera mostra d'aquest tipus contractual s'analitzà en el treball presentat en el Ir. Congrés celebrat a

\footnotetext{
${ }^{53}$ Un exemple d'aquesta costum el presenta la remissió de Maria, filla de Llorenç de Jonqueres i Maria, homes propis i sòlids del senyor Bernat de Cabrera, per raó del mas Jonquer per $2 \mathrm{~s}$ i $4 \mathrm{~d}$. per lo qual "puelle sunt assuete redemi", en aquest cas en el terme del castell de Cabrera. AEV, Capbreu del vescomtat de Cabrera, notari Joan Olivés.

${ }^{54}$ Doc. 571 de J. M. PONS I GURI, Inventari dels pergamins de l'Arxiu Històric "Fidel Fita" d'Arenys de Mar, Barcelona, Departament de Cultura de la Generalitat de Catalunya, 1984.

${ }^{55}$ En canvi el senyor de la casa de San Julià del terme de Palafolls el 1378 redimí a una dona pels $2 \mathrm{~s}$. i $8 \mathrm{~d}$. estipulats mentre que Bernat de Pineda, el 1350 ho feu per $5 \mathrm{~s}$. Doc. 223, 123 i 293 (corresponent al de la Blanca) de l'Inventari dels pergamins de l'Arxiu històric municipal de Calella, a cura de J.M. PONS I GURI i J. RODRÍGUEZ BLANCO, Fundació Noguera, Barcelona 1990. Respecta a les altres zones estudiades: J. SERRA I VILARÓ, Baronies, op. cit. J. PAGÈs, Els senyorius alodials en el vescomtat de Bas a la baixa edat mitjana. FALTA LA CIUTAT, Alzamora Artgrafica, S.A., 1987, 2 vols. i A. SERRA I CloTA, La comunitat rural a la Catalunya Central (Collsacabra s. XIII-XVI), Vic. Ed. Eumo, 1990 i A. SERRA, Economia y sociedad a lo largo del s. XIV en la Cataluña Central: Efectos de la Peste Negra en "Señorío y Feudalismo en la Península Ibérica", III, Zaragoza, 1993, pp. 449-472.

${ }^{56}$ Doc. 571 de J. Ma . PONS GURI, Inventari, op. cit.
} 
Saragossa l'any 1991, amb el títol "Señorío y feudalismo en la Península Ibérica"57. En aquell document, centrat en la població d'Osona de Roda de Ter de l'any 1385, s'hi apuntà la possibilitat que aquesta forma de contracte fos pròpia d'un nou tipus de propietari procedent del mon urbà, el qual hauria adquirit la finca rural coincidint amb el despoblament del camp, que afavorí la inversió d'aquest sector urbà en terres deshabitades. El nou propietari mostrava dos interessos molt marcats: en un primer moment aconseguir repoblar el mas per tal de poder percebre'n els beneficis, per la qual cosa oferia reduccions dels drets senyorials, i el segon objectiu se centrava en la recuperació dels mateixos drets que havia eximit anteriorment. Així doncs, s'interpretava que aquest tipus d'actuació era pròpia d'un grup social que havia aconseguit la seva posició econòmica en el sector urbà i que amb la nova inversió immobiliària pretenia fer una rèplica del sistema senyorial terratinent o fins i tot integrar-s'hi.

Posteriorment les contínues troballes d'aquest tipus de document en altres zones geogràfiques $\mathrm{i}$ amb un protagonista predominantment senyorial, han fet canviar les primeres hipòtesis. Tal com ja s'ha apuntat, l'interès dels propietaris era mantenir la mateixa estructura econòmico-senyorial, pròpia de l'etapa anterior a la crisi, caracteritzada per una forta pressió a partir dels mals usos i la remença. És a dir, cal entendre que qui practicava aquesta pressió era el sector més conservador dels senyors i que amb aquesta decisió donaven l'esquena a una alternativa econòmica que de fet fou la que acabà d'imposar-se. És per aquesta raó que cal considerar que fou un fracàs, bé perquè una part dels tinents abans de complir amb les condicions imposades renuncià al mas o també perquè es pot interpretar que aquesta nova forma de pressió senyorial fou un dels motius de la revolta remença. Per arribar a aquesta conclusió solament cal observar en quines zones tingué més vigència, tal com s'anirà presentant.

- Anàlisi interna de la varietat d'establiments emfitèutics.

Per tal d'entendre el contingut d'aquest tipus contractual, se n'ha estudiat una mostra, de la qual se'n descriu, a títol il.lustratiu, el cas del mas Ciris de Sant Esteve de Bas ${ }^{58}$. Aquest document fou expedit el 18 de juny del 1383 i subscrit entre Alamanda d'Estanyol, com a propietària, i Guillema,

\footnotetext{
${ }^{57}$ A. Serra, Economia y sociedad a lo largo del s. XIV, op. cit.

${ }^{58}$ En aquest cas s'utilitza la trancripció efectuada per J. PAGĖs, Els senyorius alodials, op. cit. p. 177. De fet cal fer notar que aquesta obra s'utilitzarà com a referència pels altres casos que shan trobat per a aquesta zona.
} 
que l'heretà desprès de la mort del seu germà. Guillema era filla de Guillem de Ciris difunt, i Saurina, encara vivent ${ }^{59}$, i estava casada amb Pere Comas de Gelats.

En aquest cas s'instauren noves condicions coincidint amb la presa de possessió del mas per part de Guillema.

Les noves condicions són:

-Dispensa del "dret de fer-hi homes i dones", és a dir, reconeixement de la remença, per espai de 15 anys ${ }^{60}$.

-En compensació, pagament de 8s durant aquests anys.

-Obligació de satisfer els mateixos censos que abans.

-Durant aquests 15 anys, obligació de tenir el mas "amansatum, acasatum et afocatum"61.

-Obligació de continuar treballant com a bon pagès per tal que la senyora Alamanda pugui cobrar correctament i en el seu temps, els censos que li corresponen.

-Passats aquests 15 anys, Alamanda recuperarà el dret "a fer homes i dones" i totes les servituds que tenien els senyors sobre el mas.

-En el cas d'incompliment de les referides servituds, la senyora Alamanda es reservava el dret a amonestar-a i, passats dos mesos, a obligar a Guillema a abandonar el mas.

- Davant d'aquesta situació o en cas de negativa a abandonar el mas, en perdrien tot dret, tant Guillema com el seu hereu.

- Per a aquesta lluïció, Guillema hagué de pagar 32 florins d'or.

Tal com es pot apreciar, aquest contracte manté les característiques de l'establiment emfitèutic:

-contracte indefinit,

-heretable,

- pagament d'un cens i ruptura del contracte en cas d'incompliment.

\footnotetext{
${ }^{59}$ És interessant constatar en aquest cas concret. el que s'ha apuntat abans sobre la supervivència de les dones. En aquesta familia es comprova com del matrimoni dels pares encara es manté en vida la dona, mentre que Guillema opta al mas per la mort del seu germà.

${ }^{60}$ Si tenim en compta que més endavant s'exigirà que el mas ha d'estar "afocat", és a dir habitat. es pot interpretar que el fer "homes i dones" vol referir-se a la remença. Es a dir doncs, que durant aquests 15 anys se'ls redueix aquest dret.

${ }^{61}$ Això equival a tenir el mas habitat i les terres treballades, tot i que s'ha de tenir en comta que Guillema està casada i per tant viu a casa del marit el que suposa que algú ha de viure-hi o actuar com si així fos.
} 
S'observa l'excés senyorial propi d'aquesta època, amb les imposicions de servituds arribant fins el lligam personal cap al mas.

-pagament d'un cens simbòlic (una gallina) durant els anys en què dura l'exempció de la remença i altres drets senyorials - que segurament es refereixen als mals usos pel mas-, per tal de mantenir intactes els drets $i$ així poder exigir-los en el moment estipulat.

-En cas d'incompliment, es perden els drets que s'adquireixen com a senyors útils tal com li correspon a l'emfiteuta, sense poder percebre la part de beneficis a què té dret en el cas de traspàs, tant per venda com un altre establiment, etc.

En el cas del mas de Roda, el senyor li permet vendre'l íntegrament, deixant establerta la part que li correspon ${ }^{62}$.

Aquesta modalitat atorga un enfranquiment provisional per fer front a les dificultats a què estava sotmesa la població del moment. Un període de 15 anys semblava suficient per superar aquesta crisi, fet que demostra a les clares que no eren plenament conscients que estaven immersos en una vertadera crisi que afectava els propis fonaments del sistema.

De la partida de documents localitzats en els dominis senyorials del vescomtat de Bas, sense incloure els que no aconsegueixen complir amb les condicions estipulades, se'n compten 8 , un altre situat a la parròquia de Baget, (La Garrotxa), un altre és el mas Soler de la parròquia de Monsolís, (La Selva) i un altre a Roda (Osona) ${ }^{63}$.

Així mateix, Pella i Forgas fa referència a una situació semblant a l'Empordà, tot i que ell solament ho localitza entre els dominis eclesiàstics: "Húbose de dictar entonces una disposición por la cual, por lo menos en los mansos de señorio eclesiàstico, los pupilos o los extraños que de nuevo habían entrado en posesión fuesen por algún tiempo libres de prestaciones y servidumbre personal" 64 .

\footnotetext{
${ }^{62}$ Arxiu Episcopal de Vic secció notarials. Notari Bernat; Capbreu de les rendes del vescomtat de Cabrera 132 v.-135 v.

${ }^{63} \mathrm{E}$ primer dels exemples citats correspon a l'establiment l'any 1355 dels' masos Aulina i Artés de Baget a Arnau de Casella per part del monestir de Camprodon. El període que se'ls concedeix és de 12 anys. F. MonTSALVATGE. Colección, vol. II, op. cit. El corresponent a Monsolís, és de l'any 1423 i consta com una pròrroga de les condicions d'alliberament de la remença i mals usos, per 10 anys més. Capbreu de les rendes del vescomtat de Cabrera... I l'altra mas de Roda és el mas Pujolar. Capbreu de ...l'escomtat de Cabrera.

${ }^{64}$ J. Pella I Forgas, Historia del Ampurdán, op. cit. p. 657.
} 
Els anys que els senyors donen de marge per a reinstaurar les pressions senyorials varien entre 3 anys ( 1 doc.), 10 ( 2 docs.), 11 ( 1 doc.). 12 ( 1 doc.), 14 (1 doc.), 15 ( 2 doc.) i 20 ( 1 doc.), que engloba més d'un mas. Així els anys en que comencen i acaben, són: 1355-1367; 1356-1371: 1383-1394; 1383-1398; 1387-1397, 1392-1395; 1397-1407; 1399-1419 i 1403-1417. Així doncs els terminis s'acabaven: un l'any 1367 i l'altre el 1371; 4 se situen a finals de la dècada dels 90 del s. XIV (1394, 1395, 1397 i 1398) i 3 a principis del XV (1407, 1417 i 1419). És a dir que es concentren al tombant del segle.

El document més antic que estableix les condicions abans esmentades, és el de l'any 1355. En aquest cas és l'abat de Sant Pere de Camprodon, que estableix a Arnau de Casella de Baget els masos Aulina i Artés, a canvi d'un cens i de la seva entrada en servitud passats 12 anys ${ }^{65}$.

L'establiment en què el senyor dóna menys temps per a restablir el règim senyorial és l'escrit el 1392 al Mallol i es tracta de la masoveria de Coura de la parròquia de Sant Privat de Bas. El senyor directe era el monestir de Ripoll. En aquest cas es tracta d'un establiment fet de nou i les condicions són les mateixes que l'anterior. Posteriorment aquesta masoveria va desaparèixer, probablement per tractar-se d'una explotació pagesa no rendible.

Cal fer notar que, de vegades, els tinents que s'avenien a aquests tractes no procedien del grup dels pagesos empobrits. Encara que no representin un grup molt destacat, són diversos els exemples de persones que adquireixen més d'un mas en aquestes condicions. Unes vegades s'hi enriqueixen com era el seu propòsit. però d'altres, passat el temps estipulat, reconeixen la seva incapacitat de complir amb les condicions i retornen el mas als senyors directes.

Entre els que gaudeixen d'una bona situació econòmica, figura G. de Reig de Sant Romà de Juanetes, que obtingué de R. de Farners, senyor de Sta. Coloma de Farners, la franquesa de 10 anys del dret sobre els homes i dones del mas Espasens, així com del foc i contínua residència. En aquest cas, a més, li concedia l'establiment dels treballs personals de les joves i batudes que cobrava pels masos Martins, Costa i Reixach de la parròquia de Sant Esteve d'Oculo. El document fou escrit el 1399. L'any 1407 l'esmentat

\footnotetext{
${ }^{65}$ Doc. 1489 del t. II de F. MontSalvatge. El Condudo de Besalli. op. cit.
} 
Guillem ja actua com a tinent del mas tot participant en la venda d'un censal ${ }^{66}$.

Era tant l'interès senyorial d'obtenir beneficis que fins $\mathrm{i}$ tot s'imposaven deures senyorials a les cabanes. La cabana en qüestió era la de Conaminassa de la parròquia de Puigpardines. El senyor directe era Berenguer de Puigpardines, veguer de Bas, i els senyors útils, el matrimoni format per Guillem de Vilagats i Cília. Per a aquest contracte, acordat el setembre de l'any 1356, els pagesos havien de pagar tasca i mitja de blat, i tasca dels raïms; i de cens, cada any, una perna del millor porc, una mitjera de civada, un parell de gallines i deu ous; i l'obligació, al cap de 15 anys, de fer una persona pròpia i sòlida amb tots els seus fills i béns, de residir personalment en la dita cabana i de fer-hi foc. Durant aquests 15 anys, com a reconeixement, havien de pagar 12 diners. Passats aquests 15 anys o millor dit 14 , el 1370, en aquesta cabana hi figurava com a resident una altra persona, Arnau de Masllopart. És a dir, per alguna raó, el primer matrimoni no fou capaç de complir l'establert i abandonà la cabana ${ }^{67}$.

La incapacitat de complir les condicions establertes consta en diversos documents. Però solament en un d'ells es pot comptar amb el del primer establiment $\mathrm{i}$ el document de la renúncia per incompliment. Aquest és el mas Maiola de Sant Privat de Bas, el qual pertanyia al vescomte de Bas. L'any 1387 fou establert a la família Perer, amb la franquesa de no ferhi homes i dones durant 10 anys. L'any 1397, acabat el termini, la família Perer no es veié capaç de complir, per la qual cosa, el 26 de juny del mateix

${ }^{66}$ J. PAGĖS, Els senyorius alodials. op. cit., II, pp. 99 i 420 respectivament. Davant la incapacitat de poder treballar totes les terres adquirides, també s'optà per sots-establir-les. Respecte a la pràctica del sots-establiment, el mateix J. Pagès es fa resso dels abusos que cometien els primers senyors útils respecta als seus estabilients. Així ho manifesta: "Val a dir que no mancaven abusos en aquest aspecte. per tal com a voltes hi hagués emfiteutes que exigiren més càrregues a llurs sots-emfiteutes que les que havien de fer i prestar al seu senyor directe; però el resultat d'això, a la llarga, era la renúncia del mas o bé terres...". Un exemple molt interessant d'aquesta situació es donà el 1379 en l'establiment del mas Pedrera de Sant Esteve d'Oculo (Bas). En aquest cas n'era la senyora útil Constança d'Aiguanegra i el senyor directa el benifet de l'altar de St. Salvador. Constança, o els seus procuradors, en aquest any 1399, pretenien sub-establir l'esmentat mas a Guillem de Pedrera Piquer amb l'obligació de posar-hi homes i dones. Donat que aquesta obligació es feu sense l'acord dels dos senyors directes, l'esmentat sot-establiment fou anul-lat. J. PAGĖS, op. cit. I, pp. 105-107.

${ }^{67} \mathrm{~J}$. PAGĖS, op. cit.. II p. 194. Certament es poden considerar abusives les obligacions que s'imposaren per una cabana, a l'igual com també eren abussius els censos que šimposaren a una cabana, de la mateixa zona, que tenia 4 jornals de bous d'extensió. En aquest cas es tracti d'un sots-establiment. El censos eren: deu ous, mitja quartera de blat, un parell de pollastres IV sous, una perna del millor porc o II sous i VI diners, repartiren tot l'any; una obra d'una persona en temps de segues i una altra per a femar. P. PAGĖs, op. cit., I, p. 107. 
any, fou establert al matrimoni format per Bernat Masjoan i Erclarmunda. En aquesta ocasió les condicions foren una mica més suaus. S'estipulà que si un dels dos cònjuges quedava vidu, l'altre podia quedar-se la casa i també que, davant d'una possible incapacitat de complir el deure de fer homes i dones, quedarien lliures sense estar obligats a pagar una remença.

De l'exposat es pot deduir que a finals de segle, tot i que els senyors pretenien recuperar la posició anterior, les circumstàncies no foren propícies i aconsellaren abandonar aquest tipus de document. Es té notícia de dos altres documents, l'un del 1420 per 6 anys $^{68}$ i l'altre del 1423 per 10 anys. En aquest cas s'especifica que és una pròrroga. El document es refereix a l'establiment acordat entre R. Sala de Sant Joan de Fàbregues i P. Pujol de Sta. Maria de Monsolís pel mas Soler de la parròquia de Montsolís. El mas, a part dels censos, està gravat amb la remença i els mals usos. Les condicions es refereixen a la prolongació de la franquesa, per la qual no han de fer remença durant 10 anys ${ }^{69}$.

També hi ha un altre grup de documents, que presenta certa relació amb els exposats abans. Gairebé a finals del s. XIV, coincidint amb l'època en que s'acaben els terminis dels anteriors, tingueren lloc alguns retorns del mas al senyor davant l'evidència que no els resultava beneficiós, molts d'ells a causa de les càrregues ${ }^{70}$.

D'aquests se'n localitzen 10 en el mateix sector del vescomtat de Bas. D'altres documents pertanyen al senyoriu del castell de Vilassar al Maresme i a Sant Hipòlit de Voltregà a Osona. També d'Osona i en concret de Torellò és el document de l'any 1427, en què s'acordarà un establiment emfitèutic pel mas Carreres. En aquest cas és molt interessant la reflexió que fa el procurador del comtat d'Osona per part del vescomte Bernat Joan de Cabrera: "En nom de Déu...Considerant que el mas Carrera de Sant Feliu de Torelló ha estat deshabitat i rònec des de molt temps a aquesta part, i encara és sense persones, per raó de les prestacions exorbitant..."71

Un document emès l'any 1396 fa referència al mas Roura de Joanetes, essent el senyor directe l'Arnau de Beuda i la senyora útil la

\footnotetext{
${ }^{68}{ }^{\circ}$. PAGÈS, op. cit., p. 280.

${ }^{69}$ Capbreu dels vescomtes de Cabrera.

${ }^{70}$ Serra Vilaró ho troba per al Berguedà, així com també s'observa a la vall d'en Bas en el treball de J. Pagès i a Osona en el d'A. SERRA, Efectes de la pesta negra a Osona, "Ausa". XIV/124 (Vic, 1990, pp. 13-30.

${ }^{71}$ F. SOLÀ, Torelló, op. cit. p. 296.
} 
Guillema Serra, la qual estava maridada amb Berenguer Serra de Joanetes, amb qui vivia al mas Serra d'aquesta localitat. Amb la transcripció del document en qüestió es poden comprovar les raons adduïdes en aquests $\operatorname{casos}^{72}$. "Jo Guillema de Serra... hereva i propietària del mas Roura de Joanetes, atenent que jo per raó de les carregues de dit mas no el puc cultivar ni fer per ell homes i dones ni altres drets acostumats, per això, per tal que l'esmentat mas per culpa de la meva part no vingui a la ruïna, de consell i voluntat del meu marit, per mi i els meus defineixo i absolc a vos, Arnau de Beuda, tot el citat mas i tot el dret a mi pertanyent..."

Uns documents dels anys 1352, 1358 i 1362 presenten les mateixes característiques que l'anterior. El primer mas pertany al monestir d'Amer, mentre que els dos següents són del monestir de Sant Joan de les Abadesses, i les propietàries són dues dones ${ }^{73}$. També presenten el mateix contingut els escrits a finals de segle i principis del següent; però els corresponents als anys 1407 i 1408 inclouen la distància i la dificultat de desplaçament, com a causa de la renúncia. També cal afegir que en aquests casos les hereves són dones que estan casades i viuen en els masos dels marits ${ }^{74}$.

L'altre exemple significatiu dels que no aconsegueixen mantenir les condicions, està protagonitzat per Francesca, muller de Ramon Tertuç del lloc del Mallol. Ella era la propietària del mas Noguer de Vallfogona (Osona), que pertanyia al senyoriu directe de l'abat del monestir de Sant Joan de les Abadesses. L'any 1399 renuncià i restituí a l'esmentat abat el mas del Noguer. El motiu era la impossibilitat de tenir el mas amansat $i$ afocat, i de fer-hi homes i dones, censos i altres drets als quals estava obligada, i finalment de conrear-lo. El testament redactat pel marit de l'esmentada Francesca, amb la deixa destinada a la participació de 17 preveres en el seu sepeli, a part d'altres deixes, ens situen aquesta família entre les benestants de la zona. Així doncs, el motiu pel qual en aquest cas (desconeixem la forma com s'adquirí el mas) es restitueix el mas al senyor directe està vinculat a l'esforç que li suposava a la senyora útil complir amb les càrregues senyorials, $\mathrm{i}$ al fet que, al no ser imprescindible pel seu sosteniment, no li compensava pels perjudicis que li causava el manteniment

\footnotetext{
${ }^{72}$ La transcripció és de P. PAGÈs. op. cit. p. 46.

${ }^{73}$ Docs. 1489,1510 i 1517 vol. II de F. Montsalvatge, op. cit.

${ }^{74}$ J. PAGÈs, II, p. 442. En aquest cas Ramona, la senyora útil de la masoveria de Quintana especifica que és per raó de la distància i dels onerosos censos.
} 
del mas. També cal tenir present que entre el lloc de procedència de la Francesca i el mas del Noguer hi ha una distància considerable. És fàcil que Francesca esperés poder-lo sub-establir, fenomen prou freqüent en aquell moment, o col-locar-hi algun fill.

L'interval de temps en que es produeixen els retorns de masos per incompliment de les condicions imposades va del 1352 fins el 1408. Tal com ja s'ha dit abans, comencen el 1352 seguit dels anys 1356, 1358, i 1362, que es corresponen al primer període. Posteriorment, hi ha un buit fins el 1393 , 1396 i 1399, per tornar amb un altre bloc als anys 1405, 1407 i 1408.

Comparant amb els terminis dels contractes analitzats anteriorment s'observa una forta coincidència el que suposa que entre finals de segle $\mathrm{i}$ principis del XV les condicions econòmiques foren desfavorables i la gent no es veié capaç de complir amb els abusos senyorials. Això podria provocar un augment de masos rònecs i problemes tant econòmics com socials.

Els documents de renúncia al mas i retorn al senyor directe no mencionen l'existència d'un altre contracte on s'estipulés un termini de franquesa. Sembla dibuixar-se un continuïsme respecte a la situació anterior amb l'obligació inherent de la residència personal, de tal forma que serien les circumstàncies adverses del moment les que impedeixen mantenir les condicions anteriors. En aquest cas el senyor no els ofereix l'oportunitat d'uns anys sense les càrregues més opressives per poder-se refer. Cal fer notar, com ja s'ha senyalat abans, que 4 pertanyen gairebé a la dècada posterior a la pesta, mentre que la resta són de finals del s. XIV i principis del XV.

\section{CONCLUSIONS: \\ REACCIONS SENYORIALS PER ZONES GEOGRÀFIQUES}

A partir de les dades fins ara recopilades es poden extreure unes primeres conclusions, que poden ser revisades a partir de noves dades o nous plantejaments. Tal com s'ha plantejat en aquest treball, les conclusions vénen donades per un anàlisi del problema remença a partir dels diferents efectes que tingueren les pestes, guerres o terratrèmols en zones geogràfiques diferents per tal de relacionar la reacció senyorial amb les seves pròpies possibilitats de recuperació de la crisi. 


\section{Nord de la zona de Girona}

Restecte a l'Empordà cal considerar que per entendre la situació d'aquesta zona en aquesta etapa cal tenir en compte que, a més de les mortaldats ocorregudes a causa de la pesta negra i els successius rebrots de l'epidèmia que marcaren tot el $\mathrm{s}$. XIV, es produïa la rebel·lió del comte d'Empúries (1384-1388) i el 1385 frenaren les tropes del comte d'Armanyac, el qual va envair la zona el 1389 fins el 1390, que provocaren una inestabilitat social $\mathrm{i}$ efectes $\mathrm{col} \cdot \mathrm{laterals} \mathrm{com}$ ara pillatges o provocacions contra el desenvolupament normal de les collites, mercats, etc. E. Rodeja, en el seu estudi de la vila real de Figueres, ha transcrit una reflexió dels figuerencs sobre els esdeveniments: "... Y como esto en muchos casos deja de cumplirse, con gran daño y perjuicio de dicha universidad, perjudicando su riqueza pública, sobretodo por su situación, casi en medio del condado de Ampurias, y del vizcondado de Rocabertí, con peligro de su total despoblación, que debemos, por todos los medios evitar, ... "75.

Bandositats, epidèmies, guerres, ....aquesta zona fou molt castigada en aquesta època. Pella $\mathrm{i}$ Forges ha presentat un gran estudi sobre el conflicte i la situació pagesa tant a nivell econòmic com social i jurídic. També reflexiona sobre la divisió dels remences, tot considerant que Girona era la zona amb major nombre de pagesos remences, distingeix dos grups. Un grup estava format pels de la part de la "Muntanya" i la Selva mentre que l'altra ho estava pels de l'Empordà. Mentre els primers foren sempre reialistes, els altres eren fidels a la política de la Generalitat ${ }^{76}$.

Un exemple de senyor d'aquesta zona molt destacat en tota aquesta etapa, fou el senyor de Rocabertí, que ja s'ha vist el tipus d'actuació que tenia. Per la seva part, S. Sobrequés i J. Sobrequés consideren: "...l' Alt Empordà era a mitjans segle $\mathrm{XV}$, en plena eclosió del gòtic, un país eminentment feudal" 77 .

Per la part del Ripollès els tres grans senyorius foren els monestirs de Ripoll, el de Sant Joan de les Abadesses i el de Camprodon. Sempre hi hagueren grans enfrontaments entre el monestir de Ripoll i els habitants de

\footnotetext{
${ }^{75}$ E. RodEJA, Figueras, op. cit. p. 15, citant el document de l'Arxiu de la Corona d'Aragó, Reg. 1896, fol. 82 i següents.

${ }^{76}$ Pella I Forgas, Historia del Ampurdain, op. cit. p. 694.

${ }^{77}$ S. SOBREQUÉS i J. SOBREQUÉS, La guerra civil catalana del segle XV, 2 vols., Barcelona. Ed. 62. 1973, vol. II, p. 124.
} 
la zona, pel fet que el monestir tendia a excedir-se en els drets jurisdiccionals que li pertocaven i arribava a enfrontar-se amb la monarquia. Fou un senyoriu molt conflictiu.

\section{La "Muntanya"}

Tal com ja he dit, he cregut convenient mantenir aquesta zona geogràfica perquè es correspon amb una regió molt homogènia, percepció molt estesa en aquella època ${ }^{78}$.

Aquesta part fou una de les zones que presentava un més alt nivell d'ocupació demogràfica al llarg de tota l'edat mitjana. No cal oblidar que ja fou un dels llocs de refugi a l'època musulmana. De fet, els vestigis arqueològics de la zona mostren una continuitat de poblament des del Paleolític. Els capbreus de la baixa edat mitjana o principis de la moderna mostren un gran nombre de masos que han desaparegut, però que mantenen el reflex del poblament anterior.

La base econòmica d'aquests espais fou bàsicament ramadera $\mathrm{i}$ agrària en llocs determinats. El moviment de numerari dels anys de la Baixa Edat mitjana indica una població amb pocs recursos econòmics. Això implicà un fort impacte de la pesta, que provocà un gran nombre de masos rònecs; masos que els mateixos senyors reconeixen que difícilment podien recuperarse. Els masos irrecuperables eren dividits en peces de terra i repartides entre diferents pagesos. Una part d'aquests es localitzaren en algunes parts de Sta. Maria de Corcó o Sant Julià de Cabrera ${ }^{79}$, mentre que un altre grup fou assimilat per pagesos els quals aconseguien d'aquesta forma ampliar el mas originari amb 3 masos més. Aquests foren els pagesos que prosperaren, com els Mascaró o els Casassa de Rupit. De totes maneres, tot i pertànyer al mateix pagès, en aquest moment no desapareix la diferència entre els masos i es continuen comptant com a masos separats amb els seus censos i drets. Això respon a l'interès del senyor de no perdre el significat d'unitat

\footnotetext{
${ }^{78}$ Aquesta zona és la compresa per les Guilleries actuals. Una visió general del tema en aquesta zona es troba en el treball A. SERRA, Análisis del conflicto y la guerra remensa en la zona de la "Muntanya" a "VII Congreso de Historia Agraria", Baeza 1995.

${ }^{79}$ Aquesta situació queda enregistrada en el capbreu del vescomtat de Cabrera.
} 
impositiva que representa el mas. Per tant, solament acceptava anul-lacions en aquells casos en què el mas fos certament improductiu com a unitat ${ }^{80}$.

Aquests masos, no obstant, això, es recuperaren a canvi de la reducció de censos, de manera que el senyor igualment veié reduïda la seva capacitat econòmica.

A nivell jurídic es pot considerar, com a força generalitzada, una reacció senyorial molt intensa. El senyor de Cruilles, petit senyor de la branca dels Cruïlles, el qual tenia el castell de Rupit, que englobava el castell del terme de Fornils, reaccionà obligant la remença i els 5 mals usos. Aquesta actitud no es contradiu amb les franqueses que atorgà a les noies dels masos amb pagaments dels $2 \mathrm{~s}$. $6 \mathrm{~d}$. o fins i tot sense cap tipus de pagament, si era per a casar-se. És a dir, afavoria els matrimonis per tal d'aconseguir augmentar la població i per tant poder recuperar masos. Aquest era un recurs de futur.

Per la seva part, el vescomte de Cabrera actuà amb molta més visió de futur. A nivell econòmic aprofità el màxim la situació, acceptant la desaparició d'aquells masos que presentaven un estat de deteriorament molt marcat, tot renunciant als drets que se'n poguessin derivar. Afavorí el conreu de les terres d'aquests masos que encara fossin productives a partir de les relacions contractuals que marcava l'establiment emfitèutic i renunciant als altres drets. I finalment en aquelles terres que es demostrava que eren improductives reduí els censos per afavorir el seu conreu. A nivell jurídic, tot i que també optà per augmentar els preus de la remença en alguns cascos, de forma més generalitzada optà per aconseguir que els seus dependents renunciessin tant al dret d'empara dels menors, com el que permetia alliberar-se si s'aconseguia fugir a la a ciutat o refugiar-se en un altre castell o senyor. Cal tenir present, però, que el seu poder tant econòmic com social no es recolzava solament amb aquestes possessions sinó en les possessions que havia obtingut la seva família en les seves empreses mediterrànies.

Respecte a les zones de la Vall d'en Bas, o la d'Hòstoles, o la d'Amer, ja s'ha vist el gran nombre de masos rònecs que apareixen, així com l'actitud agressiva dels propietaris davant la crisis. En aquesta zona es

\footnotetext{
${ }^{80}$ Una mostra clara que posa de manifest aquestes condicions es troba en la reducció que el 1429 fa el monestir de St. Pere de Casserres de les servituds personals per raó del mas Olivera. En aquesta reducció el senyor fa constar que no es podran unir els masos Olivera i el Bruguera que pertanyien a J. Bruguer. Arxiu Comarcal de Vic, "Manuscrit de les possessions del monestir de St. Pere de Casserres", p. 111v.
} 
mantingué un nivell econòmic molt feble si es tenen en compte les referències a les bordes, i més quan alguns pagesos encara pretenien especular amb aquells altres pagesos que no podien accedir a res millor. Els propietaris, per una part, recorren a oferir bones condicions durant uns anys, per a posteriorment imposar la mateixa pressió d'uns anys abans. Així es pot considerar que al segle XV s'intentava mantenir els drets senyorials. Mostra d'aquesta situació és la venda que tingué lloc el 1424, abans ja citada, de 17 masos de la Vall d'Hostoles, dels quals 6 eren rònecs i per tant deshabitats. En la venda es fa constar que s'hi inclouen els drets sobre les persones d'aquests masos. És a dir, que pretenen exigir aquest drets en aquelles persones que s'avinguessin a viure en aquests masos; sense per tant donar cap avantatge als pagesos. La reacció de la pagesia fou la d'un gran descontentament, i també d'oberta resistència

Els senyors que actuen d'aquesta forma, solen ser o petits propietaris, o membres de la petita noblesa, els quals veuen com el seu patrimoni no rendeix suficientment, però sobre tot no saben trobar la sortida de la crisis optant per una solució alternativa de futur, com ara l'increment de la ramaderia, tal com succeirà ja a finals del segle $\mathrm{XV}$ i principis del següent. Per tant, aquesta fou una altra de les zones amb una gran conflictivitat pel gran enfrontament entre dos grups amb interessos oposats ${ }^{81}$. Tant a l'Empordà com a la Muntanya, es va recórrer a oferir certa relaxació en algunes condiciones, però solament amb caràcter transitori, la qual cosa fou segurament una de causes de l'esfondrament final: no voler reconèixer que el sistema s'acostava a la seva fi.

\section{Osona}

A la part d'Osona, en concret a la plana de Vic, es poden distingir clarament dues èpoques ${ }^{82}$. L'una com a conseqüència de la pesta i l'altra al s. XV com a efecte dels terratrèmols del 1424. Del primer moment consten les reduccions de censos per aconseguir apaivagar el primer impacte, en aquelles terres que es declaren infructíferes com queda de manifest en el capbreu de Tona del 1388 o en alguns masos de Torelló. Per altra banda, els

\footnotetext{
${ }^{81}$ De fet els primers disturbis que propiciaren l'aixecament del 1362 tingué lloc justament per mantenir aquests posicionaments, en concret el senyor i els pagesos de Santa Pau.

${ }^{82}$ Un primer anàlisi dels efectes de la pesta negra a Osona fou publicat en el treball: A. SERRA, Efectes de la pesta negra a Osona. a "Ausa", op. cit.
} 
masos que en aquest moment són abandonats són masos amb poca viabilitat econòmica $\mathrm{i}$ aviat seran reconeguts com a derruïts, amb la consegüent renúncia per part dels senyos als seus drets davant l'evidència de la seva irrecuperabilitat. Aquests són els masos que al capbreu de Sant Hipòlit consten com a tals $\mathrm{i}$ part de les seves terres són aprofitades per altres pagesos per a completar el seu predi. Aquests són 10 masos que comencen a deteriorar-se en la dècada dels anys 60 del s. XIV. En la part de Roda, s'utilitza el recurs a la reducció de la pressió senyorial per un temps.

Situats ja en el s. XV, els efectes del terratrèmol es traduïren en un augment de masos deshabitats. A Taradell i a Sant Hipòlit, se'n compten amb abundància. A Sant Hipòlit, però, una part d'aquests masos eren aprofitables per altres pagesos, a l'igual com ocorregué a Rupit, i passaren a engrossir, de forma considerable la nova unitat de producció familiar. El 1437 en la zona concreta de Sant Martí de Sobremont (Sant Hipòlit) 13 masos foren repartits entre 4 famílies. D'aquesta forma es constituïren importants famílies amb una unitat de producció que s'havia multiplicat per quatre.

Jurídicament es donà una diversitat de situacions segons el senyor. El de Torelló i Gurb foren senyors durs, mentre que el de Sant Hipòlit o tona ho foren menys.

A Osona, els enfrentaments entre la petita noblesa estigueren presents des de principis del segle XIV. Entre aquests nobles, destacà un important cabdill remença, l'Altarriba.

\section{La zona costanera de Calella, Arenys de Mar i Mataró}

Observant la documentació recollida tant d'Arenys com de Calella, el primer que destaca és un gran moviment de la propietat de terres a partir de vendes o traspàs de la propietat útil a través de sub-establiments, fets que denoten una intensa activitat econòmica. Aquestes transaccions, tot $i$ que algunes d'aquestes terres procedien de masos rònecs, es realitzaven segons la forma contractual econòmica que li correspongués, però sense intervencions de tipus senyorial. Algunes d'aquestes terres són destinades al conreu de la vinya i d'altres a l'explotació del regadiu a partir de les hortes, i també s'observa una intensificació en el desenvolupament dels molins drapers. Tot plegat dibuixa una zona amb unes línies força definides per aconseguir superar la crisis. 
Ara bé, al costat d'aquesta posició, el sistema feudal continua actuant com queda palès en l'enfrontament que tingué lloc a Palafolls quan el 1389 Francesc Moragues de Palafolls es negà a capbrevar determinades obligacions, tal com pretenia el senyor de la casa de Sant Julià del terme de Palafolls, Bernat Albertín ${ }^{83}$. Tres anys més tard, el 1392 Bernat, vescomte de Cabrera, feu pagar $11 \mathrm{ll}$. a l'esmentat Francesc, per ruptura de jurament i homenatge, en negar-se a reconèixer ser home propi i sòlid de la casa de Sant Julià. Segurament cal situar aquesta resistència amb el moviment que Pella i Forgas troba en l'Empordà en aquestes mateixes dates.

Seguint amb aquesta actitud a Argentona, el 1379 en l'establiment del mas Batlle per part de P. Bosc, aquest assenyala: "... ab toes sos honors, pertinences e drets, e ab homes e ab fembres, habitants o stants en aquell mas o en pertinencies de aquell, es mas propi, soliu e affogat... ab totes servituts, exaccions, exides, intesties, cogucies, eixorquies e foriscapis $\mathrm{o} a b$ altres plens drets e servituts" 84 .

Del mateix caire fou l'actuació del senyor de Mataró el qual davant la situació dels masos rònecs demana que es reconstrueixi el mas en runes i a més els obliga, a part dels censos, a les servituts "... habeatis intratas et exitas et redempcionem hominum, jovas, traginas et alias servitutes consuetas... "85.

Respecte als altres senyors de la zona cal destacar el monestir de Breda al s. XIV, el qual a nivell jurídic actua com un senyor opressor cobrant alguns dels mals usos com l'eixòrquia o redimint a causa del matrimoni amb preus tendint a l'alça com els 5 florins que cobrà a Nicolau Oliver d'Arbúcies o els 8 florins a Margarida, la qual no consta que estigui casada. En canvi, a nivell econòmic actua com els senyors abans exposats. Per tal de tenir les terres conreades, també optà per reduir els censos per, "estimular el conreu de les terres". Durant el s. XV, es manté en la mateixa tendència optant, com la majoria dels senyors, per la reducció de censos.

El que sorprèn és l'actuació de la família Tria. Aquesta família, tot i essent persones remences del senyor de Cabrera, saberen aprofitar els avantatges que aquest senyor oferí als pagesos dels seus dominis i assoliren

\footnotetext{
${ }^{83}$ Docs. 257 i 270 respectivament de l'Inventari de pergamins... Calella op. cit.

${ }^{84}$ M. Richou, Aproximació a la Història de la vila d'Argentona a la baixa Edat Mitjana (segles XIII-XV). Universitat de Barcelona, 1985, p. 195.

${ }^{85} \mathrm{C}$. Cuadrada, El Maresme medieval: Hàbitat, economia i societat, Segles X-XIV, Mataró, Ed. Rafael Dalmau, 1988, p. 294.
} 
una situació econòmica molt pròspera tot adquirint boscos, terres, masos, etc. Però, una part d'aquest masos o bordes les sub-establien, i a més establien les aconseguides per compra-venda, obligant a la remença, fins $i$ tot per una borda com la d'en Domingo o la que tenia a Arenys ${ }^{86}$, de manera que en aquests casos s'equiparen als senyors més opressors.

Així mateix el que sorprèn és que en aquesta zona la presència de membres de la part urbana de Barcelona. no significà que aportessin una forma d'actuar aliena al feudalisme sinó que sovint emulaven la dels senyors feudals, només cal tenir present que un dels senyors més destacats fou la Seu de Barcelona i tant els castells de Mataró com el de Vilassar pertanyien a la "burgesia urbana"87.

\section{Zona d'influència del nucli de Barcelona: Provençana}

Jaume Codina ha estudiat de forma exhaustiva aquesta zona, per la qual cosa aquest apartat es basa en el seu llibre. L'autor considera que en la segona meitat del s. XIV l'Església continua dominant com a senyor amb 57 masos, seguida dels 28 dels ciutadans i els 8 reials. De fet el 1359, 5 homes de l'illa de Banyols fan homenatge com a homes propis, sòlids i afocats del monestir de Sant Cugat. Per altra part, tot i que dominen els lloguers de terres per poc temps i poc preu, el que permet un gran moviment dels arrendataris amb la conseqüent inestabilitat i la possibilitat d'especulació, l'actuació de l'Església no difereix substancialment de la descrita en les zones abans exposades. L'establiment de 1386 del mas Magnet, inculte, es fa reduint els drets senyorials del monestir de Sant Pere de les Puelles dels treballs personals que encara es mantenien, entre altres drets. Posteriorment, ja ben entrats el s. XV, l'any 1449, el mateix monestir estableix un mas amb la condició que el pagès fos propi sòlid i afogat i amb l'obligació de prestar una jova, a part dels censos ${ }^{88}$. Un altre exemple semblat es produeix l'any 1459 per part de l'Hospital de Sant Joan, en l'establiment del mas Alegret.

Respecte a l'impacte de la crisis, l'autor considera que contràriament als districtes rurals, el llogarret sembla recuperar-se de la davallada de la

\footnotetext{
${ }^{86}$ Docs. 620 i 629 de J.M a PONS GURI, Inventari, op. cit.

${ }^{87} \mathrm{C}$. CuAdrada, El Maresme, op. cit. pp. 413-414.

${ }^{88}$ En aquest cas, el document es presenta com una venda, però amb les condicions abans exposades, el que cal suposar és que deuria tractar-se de la venda del dret sobre el senyoriu útil.
} 
dècada dels anys 60 i 70 . Per altra part, mentre la població en un $75 \%$ són propietaris, els masos de la plana presenten un clar estancament.

Es pot concloure que l'Església actua de forma molt reaccionària en una zona on predominaren els petits propietaris.

\section{El Berguedà}

Aquesta zona ha estat molt ben estudiada per J. Serra Vilarò. L'autor considera que es produí una forta reacció senyorial davant l'èxode dels pagesos a zones que els oferissin millors condicions, perseguint-los fins als nous llocs i forçant a cobrar la remença. Al mateix temps observa, en la seva documentació, un augment dels preus de la remença. A nivell econòmic, es pot observar la tendència generalitzada de l'abandonament de masos, a finals del s. XIV, en aquest cas sobretot a causa de les distàncies. El tipus contractual que predominarà al $s$. XV serà el de parseries $\mathrm{i}$ masoveries sense que s'observin mostres de resistència a perdre els drets abusius que s'aconseguien a nivell senyorial, com els mals usos.

\section{La part de Lleida}

Josep Lladonosa, en la seva Història de Lleida", considera que: "...el Pallars en conjunt, es trobava amb els mateixos problemes socials que a la resta de la Catalunya vella, els mals usos, la manca de llibertat personal". Posteriorment, afegueix: "...tant al Pallars com a Ribagorça i l'alt i mig Urgell, es manifestà una inquietud semblant. El mateix podem dir del Solsonès"89.

De fet, en la promulgació del pariatge negociat entre l'abat de Gerri $i$ el procurador del comte de Pallars a l'any 1368 , entre els drets que li pertoquen al monestir, s'especifica: "...per dictum monasterium assuetis recipi et cum aliis iuribus omnibus quae solidus dominus habet in suis hominibus naturalibus et cum intestia, exorquia, cogucia et arsina, iovis, traginis batudis carrigiis..." ${ }^{n}$. És a dir que es presenta com un senyor amb una forta pressió sobre els seus dependents. De fet l'enfrontament entre els

\footnotetext{
${ }^{80}$ J. LladonOSA. Història de la ciutat de Lleida. II. Tàrrega, 1974, p. 38.

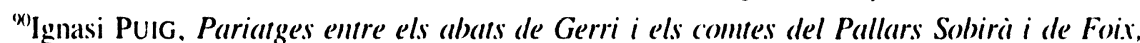
dels segles $X I V i X V$. "Urgellia". II (1979). p. 352.
} 
dos senyors es mantingué al llarg d'aquests segles provocant una inestabilitat pròpia de les bandosistats. El mateix Lladonosa percep aquest clima de bandosiatats en tota la regió de Lleida. També cal tenir presen que el comte de Foix penetrà per la Noguera Pallaresa entre 1396-1397.

Per la seva part, el comte de Pallars es destacà per la seva actuació contraria al moviment remença, coaccionant als pagesos de les seves terres per tal de que no participessin en l'organització monetària a partir dels "talls"91.

Finalment, en el vescomtat de Castellbó el mateix vescomte reconeix que davant el gran despoblament de les seves terres "...se' $\mathrm{n}$ foren anats en autres parts e terres on los bolen far bon acollimnet, sinó car nostres oficiers et los dits cònsols los auen entretenguts metent-los en sperance que nós usan de benignitat los remetorem per algun temps augune partida de les dites quèstias..."92. És a dir que aquest senyor també haguer de reduir alguns dels seus drets per frenar l'emigració tot i que era massa tard.

Es pot considerar que els senyors de la zona no afavorien que es mantingués la població oferint bones condicions. Al contrari, davant de la realitat, es mantingueren en l'opressió.

Com a conclusió final, cal ressaltar que les zones més castigades, tant per les epidèmies, com terratrèmols i guerres, foren el nord del Principat, en especial l'Empordà i les Guilleries, amb tot el Collsacabra, i totes les valls, les d'Hòstoles, d'Amer i d'en Bas. Així mateix, a causa d'enfrontaments senyorials, tota la part del Pallars també presentà una situació molt conflictiva.

\section{RÉSUMÉ}

Ce travail analyse la consequence de la mortalité, le nombre de fermes abandonnées et les réactions immédiates des propiétaires pour maintenir leurs fermes habitées tout en limitant la liberté du mouvement des "remences".

La crise peut être considérée sous de différents apects: l'adaptation du type de contract aux nouvelles circonstances qui en favorisent que les propiétaires, l'accion de rendre

\footnotetext{
${ }^{91}$ F. Carreras y CANDI. La ciutat de Barcelona. "Geografia General de Catalunya". vol. II. s.d.. p. 504.

${ }^{92}$ C. Baraut. Capbreu del rescomiat de Castellbó, op. cit.
} 
les fermes par incapacité de payer les taxes et les charges aux propiétaires, le mauvais état de la terre et la vende des fermes pour payer les charges aux propiétaires.

Dans la dernière part, on a fait la première analyse globale à partir des particularités géographiques et des points de vues des propiétaires.

\section{SUMMARY}

This piece of work analyses the impact of the mortality, the amount of abandoned farmhouses derived from it and the immediate reactions by the lords in order to maintain their farmhouses inhabited, consisting in reducing the free movement of the farmers.

The adaptation of a type of contract to the new circumstances and particularly favouring the lords; the return of some farmhouses due, on one hand to impossibility to face the burden associated to the contract, and on the other hand, to the improductivity of the land; and the need of selling the farmhouses to pay taxes and charges to the lord; are different evidences of the crises.

In the last part of this study, a first global analyses has been made based on geographical particularities and different attitudes to the crises by different lords. 